\title{
Research in progress: report on the ICAIL 2017 doctoral consortium
}

\author{
Maria Dymitruk ${ }^{1} \cdot$ Réka Markovich $^{2,3,4} \cdot$ Rūta Liepinga $^{5}$ (D) \\ Mirna El Ghosh ${ }^{6} \cdot$ Robert van Doesburg $^{7} \cdot$ Guido Governatori $^{8}$ (D) \\ Bart Verheij"
}

(C) The Author(s) 2018. This article is an open access publication

\begin{abstract}
This paper arose out of the 2017 international conference on AI and law doctoral consortium. There were five students who presented their Ph.D. work, and each of them has contributed a section to this paper. The paper offers a view of what topics are currently engaging students, and shows the diversity of their interests and influences.
\end{abstract}

\section{Introduction}

The ICAIL 2017 Doctoral Consortium was organized to promote the sharing of ideas from Ph.D. researchers in the area of Artificial Intelligence and Law, and to provide them an opportunity to interact and receive feedback from leading scholars

$\triangle$ Bart Verheij

bart.verheij@rug.nl

1 Research Center for Legal and Economic Issues of Electronic Communication, University of Wroclaw, Wrocław, Poland

2 CPNSS, LSE, London, UK

3 Department of Logic, ELTE, Budapest, Hungary

4 Department of Business Law, Budapest University of Technology and Economics, Budapest, Hungary

5 Department of Law, European University Institute, Florence, Italy

6 LITIS, INSA de Rouen, Saint-Étienne-du-Rouvray, France

7 Leibniz Center for Law, University of Amsterdam, Amsterdam, The Netherlands

8 Data61, CSIRO, Brisbane, Australia

9 Institute of Artificial Intelligence and Cognitive Engineering, University of Groningen, Groningen, The Netherlands 
and experts in the field. The Consortium took place on June 11, 2017, as a satellite event of the 16th International Conference on Artificial Intelligence and Law (ICAIL 2017, London, UK, June 12-16, 2017). The Consortium was the second of its kind, following the successful ICAIL 2015 edition in San Diego, California. Specifically, the Consortium sought to provide opportunities for Ph.D. students to:

- Obtain fruitful feedback and advice on their research projects;

- Meet experts from different backgrounds working on topics related to the AI and Law and Legal Information Systems fields;

- Have a face to face mentoring discussion on the topic and methodology of the Ph.D. with an international senior scholar;

- Discuss concerns about research, supervision, the job market, and other careerrelated issues.

Five Ph.D. candidates presented their work at the Doctoral Consortium: Maria Dymitruk, Réka Markovich, Rūta Liepina, Mirna El Ghosh, and Robert van Doesburg. Their respective mentors were Guido Governatori, Leon van der Torre, Bart Verheij, Enrico Francesconi, and Giovanni Sartor. Each presentation was followed by a lively Q\&A with the audience. The afternoon ended with a mentoring session, where mentee and mentor could discuss research, supervision, the job market, and other career-related issues, in a personal meeting. On the first day of the main conference, all candidates presented a two-minute pitch of their research.

Maria Dymitruk (Sect. 2) studies Polish civil proceedings from an AI perspective. She is interested both in technical tools supporting dispute resolution and in the legal changes needed for such innovations.

Réka Markovich (Sect. 3) investigates rights and duties using formal methods, building on Hohfeld's century-old analysis. She focuses also on enforceability, the role of the state and power.

Rūta Liepina's research (Sect. 4) addresses causality in the law, with a focus on modeling the causal and evidential relations in legal cases, aiming to connect legal theory and AI and Law research.

In the research by Mirna El Ghosh (Sect. 5), a legal domain ontology is used for the design of decision support systems. A challenge addressed is how to connect the domain ontology with logical rules.

In his research, Robert van Doesburg (Sect. 6) focuses on the scalable formal interpretation of natural language sources of norms, allowing for the modeling of legal consequences for all addressees, and of different interpretations.

As such, the Ph.D. candidates address core themes of the field of AI and Law: legal decision support (Dymitruk, El Ghosh, Van Doesburg), formalizing legal concepts (Markovich, Liepina, Van Doesburg), and legal ontologies (El Ghosh, Van Doesburg). ${ }^{1}$

\footnotetext{
1 Note on authorship: The main sections of this report have been written by the doctoral candidates (as indicated), who appear as authors of the report in the order in which they presented at the ICAIL 2017 Doctoral Consortium (https://nms.kcl.ac.uk/icail2017/dc.php). The introduction to the report was written by the organisers of the Consortium, who appear as the two last authors of the report.
} 


\section{Maria Dymitruk: the application of artificial intelligence in Polish civil proceedings}

\subsection{Introduction}

Technological development is constantly affecting justice in significant ways. Neither practitioners nor researchers of law can ignore the potential which is connected with advancement. This development and the constant evolution of the artificial intelligence capabilities brought with it gives the opportunity to improve the functioning of administration of justice. One of the ideas for such improvement are the attempts to automate judicial proceedings, including civil procedure, by creating artificial intelligence systems having the ability to judge. The application of artificial intelligence methods in order to automate the law application process requires both the creation of computer systems able to conduct numerous reasoning processes and judgement activities, and also a detailed analysis concerning admissibility of AI applications in legal proceedings. The practical use of artificial intelligence technologies in law should remain in accordance with institutional and procedural requirements of judging. ${ }^{2}$

\subsubsection{Subject of the doctoral thesis}

The subject of the doctoral thesis being prepared by me is the analysis of potential to use artificial intelligence in Polish civil procedures in the role of the adjudicator or to support the work of humans. The researches undertaken within the study will constitute an attempt to verify whether the use of computer systems created on the basis of achievements in the field of artificial intelligence can be compatible with the binding provisions of Polish law determining the shape and the character of the civil procedure. This undertaking will require an analysis of compatibility of AI applications with the requirements of Polish legal order, including in particular principles of civil procedure regulated in the Constitution (Constitution of the Republic of Poland of 2 April 1997 [Journal of Laws No. 78, item 483, as amended]) and in the code (The Act of 17 November 1964-The Code of Civil Proceedings [Journal of Laws of 2016, item 1822, as amended]). The deliberations presented in the doctoral dissertation will have their source in regulations of Polish law and Polish judicial reality. Nevertheless, because of the similarities of civil procedures principles in different countries, it is possible to relate the results of this study to other legal systems as well.

\subsubsection{Methodology of the study}

The issues connected with automation of civil procedures verified within the doctoral dissertation will generally require reference to two disciplines: to artificial intelligence in part and to law in complex manner. One of the methodological

\footnotetext{
${ }^{2}$ Maria Dymitruk is working for a Ph.D. at the University of Wrocław, Poland under the supervision of Prof. Jacek Gołaczynski.
} 
assumptions is to put the legal considerations into modern technological reality by referring to the specific methods and techniques of artificial intelligence and practical use of AI in law. The result of the adopted approach will be the need to describe current achievements of automation of legal process in the fields of AI and Law, and the analysis of the possible use of these achievements in Polish civil procedure.

The study will open with presentation of the artificial intelligence issues. This part of thesis will cover not only the definitions and the presentation of the historical development of AI, but also the description of chosen methods and techniques of artificial intelligence, which may turn out to be useful in the creation of the automatized civil procedure systems (including expert systems, artificial neural networks, fuzzy logic and evolutionary algorithms). In this chapter examples of AI applications in law will also be presented [including, amongst others, TAXMAN (McCarty 1976), HYPO (Ashley and Rissland 1987), CABARET (Skalak and Rissland 1992), CATO (Aleven and Ashley 1995), BankXX (Rissland et al. 1996), IBP (Ashley and Brüninghaus 2009) and GREBE (Branting 1991)].

The subsequent part of the study will address directly the main subject of the thesis: the issue of the admissibility of the use of AI in the process of law application in Polish civil procedures. It will be based on the analysis of binding provisions of Polish law, theoretical considerations in the field of law and in part on comparative and interdisciplinary research. The last chapter of the thesis will be devoted to the potential postulates of the application of artificial intelligence to Polish civil procedures (the content of these postulates will be determined by the previously conducted studies).

\subsubsection{Justification for the choice of the doctoral dissertation topic}

The topic of Artificial Intelligence and Law has not yet become the subject of broad scientific discussion among Polish lawyers. The decision to research into the application of artificial intelligence to civil procedures stems both from this, and from my own scientific interests (new technologies and their impact on civil law and civil procedures). The choice of the subject of the doctoral dissertation is also supported by the fact that civil procedures are the most computerized judicial procedure in Poland and so that is where the greatest hopes of automatization by using AI tools can be placed.

The Research Center for Legal and Economic Issues of Electronic Communication (CBKE) at the University of Wrocław, of which I am doctoral student, is a leading Polish research center dealing with e-justice and modern technologies. The staff and $\mathrm{Ph}$.D. students of CBKE are taking an active part in computerization of the Polish administration of justice, participating in such undertakings as the introduction of e-protocol to Polish courts (to all instances now), implementation of electronic writs of payment (e-court) and making it possible to conduct legal proceedings using online judicial proceedings (among others by filing lawsuits via the Internet). I hope that my research on automation of civil procedures will constitute an important step in the CBKE's research development and may in future contribute to the improvement of the Polish judicial system. 


\subsection{The assumptions of the doctoral thesis}

\subsubsection{Presentation of the main study problem}

The study undertaken in the thesis will constitute an attempt to verify the admissibility of using computer systems created on the basis of developments in the field of artificial intelligence as the adjudicating entity in the process of law as applied in Polish civil procedures. Both the possibility of full automation of civil procedures (hypothetical for now) giving overall control to the AI system of all functions performed by the judge, as well as the-much more realistic-opportunity to use the tools of artificial intelligence to support the judges will be analyzed.

Both these types of practical application of artificial intelligence in Polish civil proceedings will have to comply with the basic principles of civil procedure in Poland. The contents of these principles are determined by the overarching function of civil proceedings - that public authorities ensure the protection of civil relations and legal rights by judicial settlement of disputes. Basic principles of civil procedures result from the whole of the Polish legal system: starting from the Civil Procedure Code Act, through the provisions of the Constitution of the Republic of Poland, to the international agreements and European Union Law (Jodłowski et al. 2014).

The main study problem is the analysis of the admissibility to automate the civil procedure by finding out, whether the application of artificial intelligence as the judge or as a support tool for judges will reconcile with the Polish legal order. If it turned out that the use of AI in the process of law application does not adhere to the standards (guaranteed not only by Polish internal law, but also international conventions) of the court proceedings (for instance the right to court access), then a much more important question than the possibility of using artificial intelligence in law will be if it is even admissible. If the technological development characterized by the creation of a well-functioning automatic legal judging system will get ahead of the analysis of the compatibility of such solutions with law or assessment of the level of social acceptance for the use of artificial intelligence in justice, the consequences may be difficult to predict.

\subsubsection{Civil procedure principles}

Implementation of artificial intelligence into Polish civil procedure cannot take place without its compliance with the basic rules and principles governing civil procedures, including those laid down in the Constitution of the Republic of Poland. Automated civil procedures must operate in compliance with both principles of the democratic state under the rule of law, and leading ideas characterizing the content and form of Polish civil procedure. The model of these proceedings is determined by overarching principles of justice (common to all judicial proceedings) and basic principles of civil procedure. Overarching principles of justice include the principle of judicial justice, the right to court access, the principle of due process, the principle of the independence of courts, the principle of judicial independence and the principle of transparency. Among the basic principles of civil procedure you 
may find the principle of free assessment of the evidence, the principle of immediacy and the principle of verbal communication in the proceedings.

It should also be clarified that civil procedure in Poland is the group of activities performed not only by the court, but also by other authorized bodies and entities (for instance bailiffs). Complete civil proceedings may include several stages: examination proceedings (proper proceedings conducted by judge or judges during which a material or formal decision is made), supplementary proceedings (for example proceedings on exemption from court costs) or enforcement proceedings (including the execution of claims). Due to the wide scope of the studied matter and the numerous issues discussed, the reflections on automation of civil proceedings by using artificial intelligence methods will be limited in the doctoral thesis to examination proceedings (from the moment the authorized entity initiates the case to the final judgement).

As it was already indicated, the doctoral thesis will verify binding Polish regulations of law, although it should be possible to apply the results of the thesis to the legal systems of other countries as well. The majority of justice systems in the world have common standards, which characterize what the judicial process, including civil proceedings, should look like. This results from multilateral international agreements, such as International Covenant on Civil and Political Rights (see article 14 of the Covenant), European Convention for the Protection of Human Rights and Fundamental Freedoms (see article 6 of the Convention), or Charter of Fundamental Rights of the European Union (see article 47 of the Charter), but also by putting citizens of many countries under the common jurisdiction of international judicial bodies (e.g. European Court of the Human Rights in Strasbourg).

Principles of judicial justice and the right to court access The principles of judicial justice and the right to court access contained therein ensures that everyone is entitled to a fair and public hearing within a reasonable time by an independent and impartial tribunal established by law (see article 6 of the Convention of the Human Rights and Fundamental Freedoms, article 45 section 1 of the Constitution of the Republic of Poland). Assurance of each person's right to claim his rights during judicial investigation should be interpreted in close relation to the regulations which define the group of judicial bodies in Poland. For example, article 175 of the RP's Constitution:

1. The administration of justice in the Republic of Poland shall be implemented by the Supreme Court, the common courts, administrative courts and military courts.

2. Extraordinary courts or summary procedures may be established only during a time of war.

Due to the topic of the doctoral thesis, it will be necessary to analyze the rules governing the Polish legal order, determining which persons or bodies are authorized to judge. This will allow the examination of whether, according to the binding provisions of law, the judicature may be exercised only by humans, or ifpossibly — no Polish regulation implements such a requirement. The answer to this 
question will make it possible to decide whether current regulations allow full automation of the civil procedure (hypothetical replacement of the judge with the artificial intelligence system), or if the use of AI will be limited only to supporting the judge.

The scope of the research will also include interdisciplinary considerations, since there is no way to verify the possibility of providing citizens with their constitutional right of access to the court without proper analysis of the sociological determinants of the possible ways in which AI will be used in court proceedings (e.g. whether there will be societal consent to entrust the functions of the judiciary to artificial intelligence). The existence of the right to court access also has its psychological justification. The aim of civil procedures is the protection of citizen's rights when endangered or violated by other citizens or by a state authority. So the question arises: whether the automated civil proceedings will correspond to the psychological needs of the individuals, which require the state to secure his or her legal interests. The legal proceedings (and the moment of adjudication in particular) is both a social act and a psychological experience. It should persuade the individual that the decision made in his case is correct. Irrespective of the outcome of the case, the individual feels a strong need to know and understand the reasons for his legal situation (especially in case of loss). For that reason, in order to reveal full picture of the use of artificial intelligence in civil procedures, it is necessary to look at this issue from sociological and psychological perspectives also.

It should also be emphasized that basic objection I have encountered in the Polish legal environment (which is usually conservative in approach) when presenting the subject of my studies, is the accusation of the alleged attempt to dehumanize administration of justice. Entrusting the decision of legal problems to computer programs (instead of humans) appears to some as a distortion of the concept of justice. With full automation of civil proceedings there is a separation of the adjudication process from the emotional or moral sphere provided by the judge. However, it is worthwhile to indicate some statistical data, the analysis of which may lead to the conclusion that current adjudicating process in Poland is already frequently deprived of the emotional involvement of the judge. In 6th Civil Division of the District Court Lublin-West in Lublin (Polish e-court) dealing with cases in the form of an electronic writ of payment (electronic order for payment proceedings), there are currently 8 judges making decisions, 50 court referendaries (referendarz sadowy), and 68 external court referendaries (data from official government website). ${ }^{3}$ Each of them makes on average 250 decisions a day (Brenk 2014). Assuming 8-h working time (the maximum daily working time in Polish legal system as default principle), by simple arithmetic it is easy to calculate that the average time of adjudication in each case is less than $2 \mathrm{~min}$. So it seems that we already have in Poland a certain mechanization of civil procedure, however imperfect, due to the fact that it is carried out by humans and thus burdened with the risk of human error and limited by the imperfections of our body: exhaustion and limited resistance to the monotony of the actions performed.

\footnotetext{
3 https://www.e-sad.gov.pl/Subpage.aspx?page_id=44; accessed 23.03.2017.
} 
The above simple analysis of statistical data leads to the question of whether the time has come to break with certain fictions of what is involved in legal decisions: not every civil case require all the judicial competences of judges and lawyers. It is not always connected with making difficult moral judgments, operating within interpretative possibilities or determining the meaning of undefined expressions. It seems that simple proceedings can even be rather mechanical, as shown by the example of electronic order for payment, and are from the technological and utilitarian point of view, already ready for full automation. However there remain questions of legal, social and psychological admissibility of their use.

The principle of judicial independence The principle of judicial independence (article 6 of the Convention of the Human Rights and Fundamental Freedoms, article 178 section 1 of the Constitution of the Republic of Poland) is connected not only with the judicial obligation to remain independent and impartial, but also with the duty of the judge to interpret the law in a proper way. The legal system does not constitute a typical database. The Polish legal system is an example of the continental law system. It consists of norms - rules of conduct, which should be derived from the legal text. This means that the Polish legal system does not consist of provisions (editorial units of legal text), the potential identification of which will constitute no difficulty for the computer program using the advancements in the field of AI, but of legal norms included in the provisions of normative acts, to be derived by the process of interpretation.

While studying the admissibility of automation of the civil procedures using AI tools, it is necessary to analyze, whether the relevant system would be able to establish which legal norm should govern the issue to be decided on, which norm is currently binding in the legal system, and its meaning (Lang et al. 1986). An artificial intelligence system would have to be equipped with tools making it possible to interpret the law according to linguistic, systemic and functional interpretation, in order to determine the meaning of the norm, to identify its linguistic context, place it in the legal system and determine the implicit intentions of the legislator (which often means going beyond strictly legal criteria, moving to moral, political or economic assessments; Leszczyński 2003).

It is worth noting that just search for the relevant provision of law would constitute a good task for the tools of artificial intelligence, and automation of this particular stage of law application would certainly contribute to improving the speed and quality of the proceedings. Artificial intelligence techniques have currently the possibility to perform fast and accurate databases searches, much better than humans can. There already exist numerous legal information retrieval systems, which are computerized at a very high technological level and are constantly updated and supplemented in response to legislative activity of the legislature. The development of the judicature and the growth in available literature is additionally facilitating this search. The fact is that the work of the lawyer, including judges, is in a major part based on the skillful search of legal provisions or judicial rulings, and so the use of AI to support this task has huge potential.

It should also be recognised that the Polish legal system includes both norms derived from the provisions of law through interpretation and norms derived from inference rules (a contrario, per analogiam, etc.; Ziembiński 1978). Therefore a 
system supporting automated civil proceedings will face the challenge of deriving the norms from the rules, both logical and quasi logical, based on the assumptions that the legal system norms have an axiological justification. This will not be an easy task, but it is worth pointing out that it is not easy for the human decision maker either. It is not unusual in the practice of judicature that the interpretation (often risky) does not give indisputable results.

Taking into consideration that the principle of the independence of the judge is the guarantee of the appropriate functioning of justice administration, the analysis of potential use of artificial intelligence in civil procedures will require an answer to the question of whether in automated civil procedures the principle of judicial independence will be implemented in an appropriate way or if it must or should be implemented at all (since the adjudicator would not be human). Determination of this issue will cause yet more doubts: in case that the implementation of the principle of judicial independence is considered not necessary, would we still face justice or-perhaps - a different, non-judicial, way of settling civil cases.

Principle of free assessment of the evidence The assessment of the gathered evidence is the essence of judicial justice. The principle of free assessment of the evidence provides the judge deciding on a civil case with the authority to assess the evidence at his own discretion (but of course with respect to the principles of logic, rationality and life experience). Therefore no methods concerning assessment of the value and credibility of the evidence are imposed on judges as a default rule, although such assessment constitutes the substance of a decision on the dispute (Piasecki 2016).

The analysis of the admissibility of using artificial intelligence in civil proceedings may not, for obvious reasons, circumvent the issue of determining the factual state of case. The automated civil procedure system would be in this regard required to initially verify information provided by the party initiating the procedure (plaintiff or applicant) and to carry out proper evidence proceedings. Determination of the factual state-as opposed to determination of the legal basis of the decision-is not based on legal reasoning, but on cognitive reasoning, requiring that the entity applying the law to possess at least the already mentioned life experience (Leszczyński 2003). In addition, proper evidence proceedings and complete implementation of the principle of free assessment of evidence, requires not only the ability to use natural language, but also to understand human behavior (for example during witness hearings). The principle of free assessment of evidence requires from the entity adjudicating the civil case to assess such elements as: the behavior of the witnesses and parties to the proceedings during their hearings, their reactions to counter-evidence and their motives in using the right to refuse testimony (Zieliński 2017). Obviously, at this stage of artificial intelligence development, it is impossible to equip the computer system with the ability to perceive such behaviour as a human being does, but nevertheless there may be artificial intelligence solutions, which may (at least in part) enable the determination of the factual state of the case by the computer program. Some systems are said to have the "ability to learn": neural networks (capable of updating themselves during actions and able to generalize the knowledge) (Russell and Norvig 2014), systems based on fuzzy logic, in which between state of 0 (false) and state of 1 (true) there 
are intermediate values, which determine the degree of belonging of an element to a set (Kisielewicz 2011), or advances in the scope of understanding and use of the natural language by artificial intelligence systems (Russell and Norvig 2014).

\subsubsection{Application of artificial intelligence in civil proceedings postulate}

The study on the admissibility of automating the civil proceedings by analyzing the implementation of fundamental principles of civil procedure will allow the derivation of postulates concerning the possibility of the real use of AI in Polish justice system. Depending on the results of the considerations of previous sections, these proposals will include full or partial automation of civil proceedings (perhaps only less complicated types of proceeding (Cf.: electronic writ of payment, European order for payment procedure, registry court proceedings or real estate register proceedings) and application of the AI as the judge's support system.

Special attention will be given to the already twice mentioned electronic writ of payment proceedings, implemented into the Polish legal order in 2010. Implementation of 'e-court' was intended to improve pursuance of uncomplicated claims by giving the possibility to fill and deliver procedural documents in an electronic way. The aim of implementing the electronic writ of payment proceedings was to improve settling of civil cases by relieving the traditional courts from investigating minor disputes (Góra-Błaszczykowska 2016). In fact, in 6th Civil Division of the District Court Lublin-West in Lublin a huge amount of cases is so settled; in order to illustrate: in the first half of $2017,1,278,590$ cases were brought to e-court, while the total number of cases submitted to Polish common courts at this time is calculated as 7,851,746 (Publication of the Ministry of Justice Podstawowa informacja o działalnosci sadów powszechnych-I pótrocze 2017 r. na tle poprzednich okresów statystycznych). ${ }^{4}$ The analysis of the presented statistical data concerning average time of resolving the cases in the electronic writ of payment proceedings brings on considerations of full automation of this proceedings. However there arise questions as to whether binding legal frameworks of civil procedure allow such automation. It turns out that the question on admissibility of substituting a judge adjudicating case with a computer system is not completely devoid of sense and is not of purely hypothetical character.

It should also be stressed that application of artificial intelligence tools in law should not only be considered in relation to the improvement of justice. Much more important is the increase in the quality of judging rather than reducing the costs or involvement of judges in work. The purpose of creating the automated judging systems in law should be improvement of justice, and not the growth in the number of low quality of rulings. It is extremely important with respect to the studies conducted by J.J. Dijkstra, which indicate that in cases where the supporting systems based on artificial intelligence were used in order to support judges (in order to 'advise' only), the outputs of such systems were uncritically accepted by judges, without verification. The 'power of persuasion' of these systems was so significant that in cases of coexistence of two sources of advisement: computerized

\footnotetext{
${ }^{4}$ https://isws.ms.gov.pl/pl/baza-statystyczna/publikacje/download,2779,0.html.
} 
and human, the users chose advice from computer system, considering it to be more objective and rational (Dijkstra 2001).

\subsection{Conclusion}

The result of the studies conducted in the doctoral thesis should be an answer to the question of whether the application (even partial) of the artificial intelligence as the adjudicator of the civil procedure-the entity responsible for its proper performance, outcome and justification for its decision-is possible. The aim of the thesis is to examine, whether in such automated proceedings all principles governing the civil procedure will be fulfilled. The answer to that question will allow assessment of the possibility of using the AI tools in Polish civil procedure (1) without the necessity to amend the provision of law, (2) by partial or substantial change of legislation, or (3) by creating brand new fully automatized non-judicial solution on settling the civil disputes.

The analysis of the above issues may indicate the direction of evolution of the Polish civil proceedings for the coming decades. The application of artificial intelligence in civil procedure has the potential to change, modernize and improve the functioning of Polish justice (suffering from numerous problems, including critical approach of Polish society to the quality of judging in Poland), by inter alia accelerating the judicial proceedings, unifying the judicature, increasing the access to court and reducing court fees. The research conducted in the doctoral thesis may provide an impulse to start a large scale scientific discussion on the possibility and propriety of AI application in the Polish judicial system, but may also be the basis for formulating proposals addressed to Polish legislator.

\section{Réka Markovich: deontic logic and formalizing rights. Actions, agents and relations in the Hohfeldian theory and its formalization}

Hohfeld's analysis of the different types of rights and duties is highly influential in analytical legal theory. Yet a century later, the formalization of his theory remains, in various ways, unresolved. I have been developing my own uniform approach to formally representing Hohfeldian conceptions. This pursuit assumes that the formalization of legal concepts both helps to clarify our understanding of legal theories and concepts, and contributes considerations about deontic logic and computer science to the foundations of AI applications. My starting point is the critiques of Makinson (1986) and Sergot (2013) and comments on the theory of normative positions developed by Kanger and Kanger (1966) and Lindahl (1995). I aim, on the one hand, to provide solutions to what they perceive as shortcomings or limitations of classical approaches, starting with the same axiomatical background. On the other hand, I incorporate various considerations from legal theory that I consider fundamental to formalizing law (as well as understanding, grasping what being law consists of). The formal system I develop is based on state enforcement in the case of the Claim-right's group of rights and duties, and the Power's dutygenerating potential in case of the Power's group, maintaining throughout the 
Hohfeldian intention that these rights and duties are sui generis and inherently relational ones. The formal system attained aims to describe how the system of rights works, how specific types of rights interact with actions or refrainings resulting in new rights and duties. ${ }^{5}$

\subsection{General background: the many faces of 'right'}

In 1913 Wesley Newcomb Hohfeld set out to clarify the notion of a right (Hohfeld 1917). His starting point is that the word 'right' is overused and bringing to the fore the possible meanings - the exact legal conceptions-behind it would allow us to see with clarity what we refer to in the various cases.

The well-known system of correlative pairs of rights and duties he built can be reconstructed in the following diagrams:
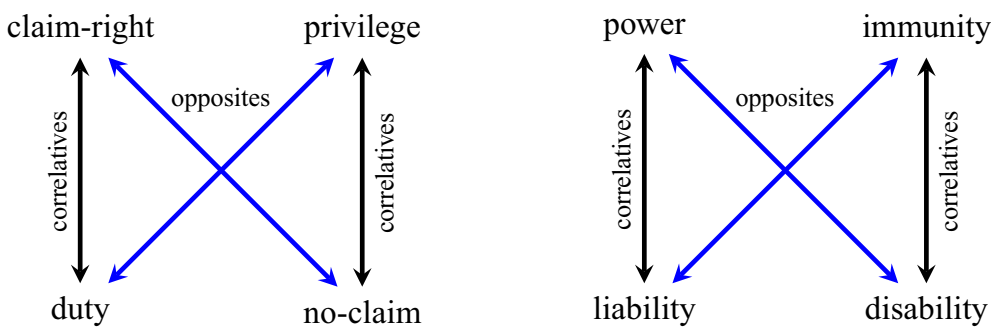

First let us examine the group on the left. If I have a parcel of land, I have a privilege (freedom) to walk through it. This means that other people have no claim that I do not go through. This parcel being mine means that others have the duty to stay away: I have the claim-right towards them to do so. As the diagram indicates, Claim-right and Duty always go together. The same is true for the correlative pair of Privilege and No-claim. As the latter label shows: No-claim is the opposite of having a claim-right. We have a privilege to do something exactly when we don't have a duty to refrain from it; more exactly, as Hohfeld emphasizes: "always, when it is said that a given privilege is the mere negation of a duty, what is meant, of course, is a duty having a content or tenor precisely the opposite to that of the privilege in question" (Hohfeld 1917).

The group on the right hand side exhibits a very similar structure; there are various points of difference between the groups though. Hohfeld already laid down that the rights (powers) in the second group are above the first group's rights in a sense: with power-rights (but not with claim-rights) one does (or does not, in the case of Disability) have the possibility to change legal positions; for instance: if I have a parcel, I have the power to sell it, but selling it changes my claim-rights, privileges, and actually my powers connected to it. Therefore the members of the second group are usually considered higher-order rights. Among others, Fitch (1967) and Makinson (1986) argued for considerations according to which the

\footnotetext{
5 Réka Markovich is working for a Ph.D. at Department of Logic, Eötvös Loránd University, Budapest, Hungary under the supervision of Zsófia Zvolenszky.
} 
difference seems to be more sophisticated. Fitch emphasized that the nature of the expressed modalities is different: while we can call the members of the claim-right group 'deontic modalities', the power group involves some kind of capacity, so calling them 'capacitative', rather than 'deontic modalities' might be more exact. Makinson adds that there are structural differences, for example, while if we do something without a permission (which, practically, is the same as Hohfeld's Privilege), we have to expect a sanction, by contrast, if we do something without power, we do not actually do not do it. Such observations are crucial when formalizing Hofeld's notions.

From the viewpoint of deontic logic, the virtue of the Hohfeldian system is that it handles agency - this is the point of correlativity: according to Hohfeld, someone's right always involves someone else's duty, and the other way around. Rights and duties do not exist on their own: being someone's right and someone else's duty inheres in their essence. This correlativity is crucial: it helps us decide whether a right/duty exists on the basis of the correlative duty/right's existence, possibility, acceptability... So this is a point of great importance on which I build my proposal providing formal descriptions of the Hohfeldian conceptions.

\subsection{Major underlying considerations in formalization}

\subsubsection{Relationality and defining directed obligations}

While relationality has been found fundamental in the reception of Hohfeld, it is one of the main points Makinson and Sergot considered as shortcomings of the most notable formalization done by Kanger and Kanger (1966), later Kanger (1985), and Lindahl (1995). Makinson (1986) stresses that Hohfeld's theory is resolutely relational; he moreover deems it necessary to introduce some explicit indexing of counterparties in the formal representation in order to properly capture the full relationality of rights relationships-even if this might lead to redundancy in some certain contexts. Makinson lays down the informal definition-like description of a rights relation where the bearer and the counterparty are explicitly built on:

$\mathrm{x}$ bears an obligation to $\mathrm{y}$ that $\mathrm{F}$ under the system $\mathrm{N}$ of norms iff in the case that $\mathrm{F}$ is not true then $\mathrm{y}$ has the power under the code $\mathrm{N}$ to initiate legal action against $\mathrm{x}$ for non-fulfillment of $\mathrm{F}$

This tradition of defining the counterparty is called claimant theory as it identifies the counterparty with the claimant. By this suggestion, though, Makinson-and other advocates of claimant theory, like Wellman (1990)_provide a kind of definition of what a directed obligation is (and considering the correlation and the directedness of the obligation, they practically describe the claim-right of $y$, too). The obvious difficulty with this_-intuitive-sounding-definition (as Sergot (2013) also points out) is the right-left direction of the biconditional: $y$ can initiate a legal action against anyone without having a claim-right originally. It's just that he won't win the case. Involving some kind of expectation of success in the definition would bring us closer to the solution, a point Sergot raises in Sergot (2013). 
However, an expectation of success doesn't in itself reveal the nature of Duty or its correlative, Claim-right. It shows some correlation in a statistical sense providing a legal realist approach, but does not explain what Duty is. In my formalization, on the one hand, I use the notion of a directed obligation introduced-following the Makinsonian considerations-by Herrestad and Krogh (1995), but expand it to all the active rights and duties, since in the Hohfeldian system, all right positions are relational; on the other hand, I demonstrate how the expectation (Sergot 2013) mentions comes about and what it means to consider Claim-right as a right (and Duty as an obligation)_-defining in this way what they mean and how they work.

\subsubsection{First group's formal representation: enforceability by the state}

Makinson's definition above building on counterparties points to another (if not the most) important feature of legal rights ${ }^{6}$ from a legal theoretical viewpoint: the possibility of seeking remedy in court. The possibility of seeking remedy in court is a well-grounded expectation in western legal culture: the Declaration of the Rights of Man and Citizen (Approved by the National Assembly of France, August 26, 1789), after listing the rights, declares in the paragraph before the last: "Any society in which no provision is made for guaranteeing rights (...) has no Constitution." Considering this issue a bit more generally: among norms, state enforcement is the differentia specifica of legal ones. It might seem intuitive to regard sanctions as the hallmark of a legal norm, but this does not hold up to scrutiny: for Catholic people, going to Hell constitutes a sanction in the case of religious norms; also, being ostracized can be highly unattractive, which is a reason behind following social norms. But none of these norms has the State behind them. And while rights and, especially, duties as notions can be associated with morality and ethics, too, Hohfeld himself considered these notions as fundamental legal conceptions. Therefore it seems natural, reasonable, and justified to capture their essence by building on what specifies make them legal rights and duties, ${ }^{7}$ just as Makinson did. In my proposal, however, Claim-right rather than Power plays the crucial role in describing the possibility of seeking remedy in court.

\subsubsection{Clarifying the role of the state}

The correlative nature of rights and duties is well embedded in legal thinking: showing the impossibility or bizarreness of a duty often serves as a political argument against the acceptability of the correlative (human) rights. And the role of

\footnotetext{
${ }^{6}$ In my dissertation I restrict the interpretation of Hohfeldian notions to the legal one. My reasons for doing so come from the fact that Hohfeld himself defined fundamental legal conceptions, and actually discussed judicial reasoning and situations, which latter can serve an argument to the premise I explicate above on binding legal rights to state enforcement. If anyone feels this premise too strong to swallow, they should read my theory as one which follows the tradition of claimant theories, describing how rights and duties work within the legal system from the judicial viewpoint, without accepting that this is the way of defining what a directed obligation means.

7 This choice might seem at first glance a strict legal positivist's approach, but actually this restriction is exactly the step through which we avoid such a commitment: we do not describe rights in general in this way: we only define legal rights.
} 
the State is and often used argument in these discussions, meanwhile this issue in itself is highly disputed. (For examples see Markovich (2015)). In my proposal I aim to clarify how and when the State is involved in providing, ensuring and enforcing rights in order to make the role of the State more clearly - and formally - capable of being referred to.

\subsubsection{Formal representation of power: duty-generating potential backed by constitutive rules}

Beside handling counterparties, Sergot declares formalizing Power as the other limitation of the theory of normative positions. As mentioned above, the higherorder property of the second group of rights comes from the fact that "this group is concerned with changes of legal/normative relations" (Sergot 2013). Fitch's and Makinson's findings tell more, though: the formal representation has to give an account of the special capacity involved into a power and the incapacity to actually perform the given act in the power's absence. But as Sergot (2013)—referring to Makinson (1986) — points out in his article on normative positions, "it has long been understood that 'power' in the sense of (legal) capacity or 'competence' cannot be reduced to permission, and must also be distinguished from the 'can' of practical possibility." Connected to that, Sergot also mentions his paper coauthored with Jones and Sergot (1996) in which they "argue that 'power' in this Hohfeldian sense is to be understood as a special case of a more general phenomenon, whereby in the context of a given normative system or institution, designated kinds of acts, performed by designated agents in specific circumstances, count as acts that create specific kinds of institutional relations and states of affairs. This switches attention from the formalisation of permission to the formalisation of the counts as relation more generally." In agreement with this, in my approach I call this capacitative feature of Power 'potential' and I try to pursue this idea of 'counts as' by capturing this feature borne by power and acts together. It might be considered obvious-as Sartor also discusses them together in his thoughtfully constructed formalization of rights in Sartor (2006), as do others listed in Grossi and Jones (2013) - that the nature of rules we have to build the notion 'count as' on is the notion of constitutive rules, since these rules constitute an activity the existence of which is logically dependent on the rules (Searle 1995). But if we look 40 years earlier, in Rawls (1955) we find the exact characterization Makinson points at in the case of Power: contrary to summary rules, practice rules are what define an action: if the rules are not followed, we are not engaged in the defined activity.

\subsection{Formalization: legal consequences, logical consequences}

In order to describe formally what having different rights and duties-together with given actions-means, I have been developing a formal system $^{8}$ aimed at representing formally what Hohfeld meant by differentiating them, and showing what conditional consequences they have within this system. These consequences

\footnotetext{
${ }^{8}$ Earlier versions of it can be found in Markovich $(2015,2016)$.
} 
therefore are at the same time both legal and logical. Since my starting point was the critique of the theory of normative positions, and my aim is to provide a comprehensive theory about the Hohfeldian conceptions, I started from the same axiomatic background, namely SDL (Standard Deontic Logic) and ET (Equivalence + T, which comes from Chellas (1980), and includes a simple 'sees to it that' operator containing only the rule of the interchangeability of equivalents and the Taxiom in order to have successful actions). I use iteration of this "simplified" STIT operator to capture the real act bound by the deontic_-and capacitative-operators (denoting the rights and duties). Of course, I needed to introduce these into the language (usually using the initial letters of rights as operator notations, that is, $\mathbf{C R}$ is for Claim-right, $\mathbf{O}$ is for Duty, $\mathbf{P R}$ is for Privilege, $\mathbf{N C}$ is for No-claim, $\mathbf{P}$ is for Power, $\mathbf{L}$ is for Liability, $\mathbf{I}$ is for Immunity, and $\mathbf{D}$ is for Disability) in such a way that they express their being assigned to agents in order to be able to describe counterparties. Using the notion of directedness - introduced by Herrestad and Krogh (1995) and others-is necessary, but not just in the case of obligation, it is also needed for the other active right positions. We use agent variables $x, y$, an agent constant $j$ standing for judiciary, and propositional letter $F$ standing for a given state of affairs.

The basis of our semantics is a finite set $A$ of agents. For a set $W$ of possible worlds and the set $A$ of agents write

$$
\mathfrak{F}=\left\langle W, f_{a}, R_{a, b}^{O}\right\rangle_{a, b \in A}
$$

where $f_{a}: \wp(W) \rightarrow \wp(W)$ is a function and $R_{a, b}^{O} \subseteq W^{2}$ is a binary relation.

Models are structures

$$
\mathfrak{M}=\left\langle W, f_{a}, R_{a, b}^{O}, v\right\rangle_{a, b \in A}
$$

where $v$ is a valuation function for atomic propositions: $v: \Phi \rightarrow \wp(W)$

Our modal language is given by

$$
p \in \Phi|\varphi \wedge \psi| \neg \varphi|\perp| E_{a} \varphi \mid O_{a \rightarrow b} \varphi
$$

for $a, b \in A$, where $\Phi$ is the set of propositional letters.

$$
\begin{aligned}
& \text { For } \mathfrak{F}=\left\langle W, f_{a}, R_{a, b}^{O}\right\rangle_{a, b \in A} \text { and evaluation }\|\cdot\|: \mathbf{L} \rightarrow \wp(W) \text { we let } \\
- & w \models p \Leftrightarrow w \in\|p\| \text { for propositional letters } p \in \Phi . \\
- & w \models \varphi \wedge \psi \Leftrightarrow w \models \varphi \text { AND } w \models \psi . \\
- & w \models \neg \varphi \Leftrightarrow w \forall \varphi . \\
- & w \models \mathbf{O}_{a \rightarrow b} \varphi \Leftrightarrow \forall w^{\prime}\left(w R_{a, b}^{O} w^{\prime} \Rightarrow w^{\prime} \models \varphi\right) \\
- & w \models E_{a} \varphi \Leftrightarrow w \in f_{a}(\|\varphi\|)
\end{aligned}
$$

The first things to set forth in our formal language are the relations between the rights and duties to emphasize their relationality. The basic equivalences describing our correlative pairs are the followings: 
Claim-right and Duty:

$$
\mathbf{C R}_{x} E_{y} F \Leftrightarrow \mathbf{O}_{y \rightarrow x} E_{y} F
$$

Privilege and No-claim?

$$
\mathbf{P R}_{x \succ y} E_{x} F \Leftrightarrow \neg \mathbf{N C}_{y} \neg E_{x} F
$$

Power and Liability

$$
\mathbf{P}_{x \rightarrow y} E_{x} F \Leftrightarrow \mathbf{L}_{y} E_{x} F
$$

Immunity and Disability:

$$
\mathbf{I}_{x} E_{y} F \Leftrightarrow \mathbf{D}_{y \rightarrow x} E_{x} F
$$

The fact that directedness is present in the case of each right and duty in the Hohfeldian system does not mean that undirected rights and duties do not belong to it, or could not be expressed. For instance, if we can derive the formula $\mathbf{P R}_{x \succ y} E_{x} F$ to all (finitely many) agents, then we can derive that $\mathbf{P R}_{x} E_{x} F$, that is, $x$ (really) has the privilege to see to it that $F$. Passive rights and duties (Claim-right, No-claim, Liability, Disability) work in the same way from the generalization point of view (but formally look a bit different if we require agent-indexed action operators being in the argument of the deontic one). There are cases where this general way is the standard to describe a given right: for instance in rights handled by criminal law (like the right to physical integrity, or even the right to life) where the structure is that everyone has a claim-right against everyone (else) ${ }^{10}$ not to commit the given felony. This can be formally represented in the following way:

$$
\bigwedge_{x \in A} \mathbf{C R}_{x} \bigwedge_{y \in A} E_{y} \neg E_{y} F
$$

The situation is similar to the type of rights Bentham calls 'vested liberty', or von Wright in Von Wright (1963) calls simply 'right': the ones by which we don't just have privilege to do something, but there is also a prohibition to everyone else on interference. These can be described in the following way:

$$
\mathbf{C R}_{x} E_{y} \neg E_{y}\left(\neg E_{x} F\right)
$$

for every other agent $y$ (of whom we have an arbitrary large but finite set).

As explicated above, in order to say something comprehensive about the nature of each right, in the case of the first group of rights and duties, we build on enforceability, as Makinson does, but instead of Power, we use Claim-right as a crucial notion. What does it mean to have a claim-right, what kind of successexpectation can we have when initiating a litigation? $X$ having a duty towards $y$ to see to it that $F$ means that if $x$ does not see to it that $F, y$ has a claim-right towards

\footnotetext{
9 In case of privilege's relationality the arrow does not seem expressive enough, the symbol $\succ$ has been chosen according to its form showing somehow who the agent is whose claim-right we are free from.

${ }^{10}$ Constraints on agent variables can be added.
} 
the judiciary that it see to it that $y$ sees to it that $F$ : that is, the original counterparty will have a claim-right to state enforcement. Formally:

$$
\mathbf{O}_{x \rightarrow y} E_{x} F \leftrightarrow \neg E_{x} F \rightarrow \mathbf{C R}_{y} E_{j} E_{x} F
$$

Why without Power? If we define (counterparties of) Claim-right and Duty with Power, we lose a crucial difference between the ability of having rights and the ability to change them. This difference is very well represented in civil law countries's legal terminology as having distinct, well defined terms for them: for instance 'jogképesség' and 'cselekvőképesség' in Hungarian, 'Rechtsfähigkeit' and 'Handlungsfähigkeit' in German, or 'zdolność prawna' and 'zdolność do czynności prawnych' in Polish (all respectively); meanwhile the English legal terminology is not precise and transparent on this issue, maybe 'legal capacity' is the closest expression to describe the ability of having right, and 'legal competence' or 'capacity to act' to describe the ability to change them. Every person has the first, but not everyone has the second: children and people lacking mental soundness partly or completely lack the capacity to act. Initiating a legal action-for which power is needed, indeed-is about asking the judiciary to decide the given case (justly). What (7) is intended to show is the deep structure about consequences of having a claimright (or a duty on the other side), this is how it is in law, ${ }^{11}$ it is legal metaphysics. ${ }^{12}$ Considering the shown deep structure of a pair of Claim-right and Duty as legal metaphysics makes a necessary formal step natural: the step of involving a legal necessity operator (with which unwanted consequences of a material conditional that Makinson already mentioned in relation to his informal definition can be eliminated):

$$
\mathbf{O}_{x \rightarrow y} E_{x} F \leftrightarrow \square\left(\neg E_{x} F \rightarrow \mathbf{C R}_{y} E_{j} E_{x} F\right)
$$

The fact that a new claim-right arises - this time against the judicature-explains why people have some expectations of success, which Sergot suggested adding somehow to the Makinsonian definition, when they initiate in a legal action having originally a claim-right. But to describe how it comes to the picture, we don't need to include the power to initiate the legal action.

Saying of (8) that it is the deep structure of rights also means we can (actually, we need to) refine it according to the given legal system handling a given right, in order to describe more precisely what happens in law: the phenomenon to involve in private law is compensation; and in criminal law, it is sanction (or punishment). In addition, we need to express in the case of criminal law that all of as have the right that no felony be committed. With these refinements we get the following formalizations of rights in private law and criminal law, respectively:

$$
\mathbf{C R}_{y} E_{x} F \leftrightarrow \square\left(\neg E_{x} F \rightarrow \mathbf{C R}_{y} E_{j}\left(E_{x}(F \vee C)\right)\right)
$$

\footnotetext{
11 Or this is how it should be in law-as Hohfeld had some difficulty in identifying his theory as descriptive or normative-at least his readers surely do. We accordingly can phrase the proposal in two ways.

${ }^{12}$ I thank John F. Horty for suggesting this expression to describe what this formula is intended to show.
} 


$$
\bigwedge_{x \in A} \mathbf{C R}_{x} \neg \bigvee_{y \in A} E_{y} F \leftrightarrow \square\left(E_{y} F \rightarrow \bigwedge_{x \in A} \mathbf{C R}_{x} E_{j} S_{y}(F)\right)
$$

Hohfeld defined Privilege and No-claim as the lack of the given duty and claimright, respectively:

$$
\begin{gathered}
\mathbf{P R}_{x \succ y} E_{x} F \Leftrightarrow \neg \mathbf{O}_{x \rightarrow y} \neg E_{x} F \\
\mathbf{N C}_{x} E_{y} F \Leftrightarrow \neg \mathbf{C R}_{x} E_{y} F
\end{gathered}
$$

and as so we do not assign separate descriptions to them.

What about Power and the rights and duties connected to it? How to express them formally? The formalization has to point out the difference between the two Hohfeldian groups. Hohfeld provides a lot of examples of Power, but the most concrete remark we can use for the formalization is about the correlative concept of Liability: Hohfeld says that "it is a liability to have a duty created". From the examples we know that it is not only a duty (and a claim-right with it) that can arise from someone using her power, but privilege, and power or immunity too. We can formalize therefore Power (using its equivalence with liability in mind) in the following way (where $F^{\prime}, F^{\prime \prime} \ldots$ are state of affairs-which are not independent from $\mathrm{F}$, explanation comes later; and $v^{\prime}, v^{\prime \prime} \ldots$ are agent variables):

$$
\mathbf{P}_{x \rightarrow y} E_{x} F^{c} \leftrightarrow \square\left(E_{x} F^{c} \rightarrow\left(\mathbf{O}_{y \rightarrow v} E_{y} F^{\prime} \vee \neg \mathbf{O}_{y \rightarrow v^{\prime}} E_{y} F^{\prime \prime} \vee \mathbf{P}_{y \rightarrow v^{\prime \prime}} E_{y} F^{\prime \prime \prime} \vee \neg \mathbf{P}_{y \rightarrow v^{\prime \prime \prime}} E_{y} F^{\prime \prime \prime \prime \prime}\right)\right)
$$

There are some crucial points in this formalization worth noting. We can have power only on special actions: that's what is indicated with the index $c$; later I explain its meaning, just like what the connection is between $F^{c}$ and $F^{\prime}$-s (but what we need to see already now that the $F^{\prime}, \ldots, F^{\prime \prime \prime \prime}$ are different state of affairs, as otherwise the consequent part of the conditional would be a tautology). A power is also a power when it is not used: the conditional is to express the potential that is there. The legal necessity operator plays the same rule as in the case of duty. There are also some important remarks about the agents in (13): unlike in case of rights and duties in the first Hohfeldian group, in case of Power and related rights $x$ and $y$ can be the same since we can have power to change our own legal positions; and it also can be the case that $x$ and $v$ (or $v^{\prime} \ldots$ ) are the same.

Let's see what $F^{c}$ and $F^{\prime}$-s are. The $c$ in the index is supposed to indicate that we can have power to see to it states of affairs which are constituted by the law: by constitutive rules. These rule looks like the following formula; that is, an action like this is built up in the following way:

$$
F^{c}: U\left(\mathbf{O}_{y \rightarrow v} E_{y} F^{\prime} \vee \neg \mathbf{O}_{y^{\prime} \rightarrow v^{\prime}} E_{y^{\prime}} F^{\prime \prime} \vee \mathbf{P}_{y^{\prime \prime} \rightarrow v^{\prime \prime}} E_{y^{\prime \prime}} F^{\prime \prime \prime} \vee \neg \mathbf{P}_{y^{\prime \prime \prime} \rightarrow v^{\prime \prime \prime}} E_{y^{\prime \prime \prime}} F^{\prime \prime \prime \prime}\right)
$$

That is, $F^{c}$ are states where a special utterance has been made (U). These utterances are about changing someone's rights. These utterances are usually institutionalized: in case of a purchase, for instance, we do not say things like "from now on, I have the privilege to use this bar of chocolate, you have the claim-right that I pay its price to you, and after that I will have the power to sell it...", we only say "I buy it"- 
since we all know what a sale means, it is written in the civil code (and they in this case realize the a manageable and effective "technique of presentation" Ross assigned to constitutive rules in Ross et al. (1957)). Or, if we did not have the benefit of a proper discipline, we do not even say a word in the shop, just take the chocolate and put the money on the counter. That is, an utterance is understood in a broad sense including implicit conduct, too. Sale, wedding (contract of a wedding), testamentary disposition, eviction, transferring one's interest are all $F^{c}$-s, more exactly, $E_{x} F^{c}$-s, that is making legal statements. We know which $F^{\prime}$-s are involved in the change by making a given legal statement from the legal rules behind: they can be written in the legislative rules, or in contracts - these background constitutive rules serve as functions when assigning $F^{\prime}$-s to $F^{c}$-s. Obviously, this approach invokes the theory of speech acts, but, again, we consider these utterances in a broad(er) sense (than they usually are in speech act theories).

With Immunity and Disability, the case is the same as it was with privilege and no-claim: these legal positions are just the lack of the given liability and power, respectively, that is:

$$
\begin{gathered}
\mathbf{I}_{x} E_{y} F^{c} \Leftrightarrow \neg \mathbf{L}_{x} E_{y} F^{c} \\
\mathbf{D}_{x \rightarrow y} E_{x} F^{c} \Leftrightarrow \neg \mathbf{P}_{x \rightarrow y} E_{x} F^{c}
\end{gathered}
$$

\subsection{The role of the state}

In these formulas there is no agent called 'State'. What is the role of the State then? Judiciary's role is obvious, it is included in the formulas-but judiciary is only one power (now in a Montesquieunian sense) of the State. It is not the only one involved, though: the legislature has the task (and responsibility in case of undertakings in international contracts) of ensuring rights. When a constitution says that the State guarantees a right, what does that mean? It means that the State guarantees the validity of biconditional(s) (8) (and (13)). How can a State guarantee the validity of a biconditional? By creating a legal system ${ }^{13}$ that obeys (can be described by) a logic in which these biconditionals are valid.

Could it be otherwise? Well, the usual comment here-concerning the general relation between logic and law-is that legal validity is actually insensitive to logical validity. ${ }^{14} \mathrm{~A}$ legal system can be legally valid without maintaining consistency among rights and duties. But to say a legal system really contains a right means that the legal system obeys a logic having these biconditionals valid. And this is what is expressed in paragraph cited from the Declaration of the Rights of Man and Citizen.

\footnotetext{
13 It's better to say 'legal system' instead of 'system of norms' since by and in the formulas we considered the legislature and judiciary too.

14 Here we consider legal validity as the existence of a legal norm: it has been created in the prescribed way (procedure), by the agency who has the power to create it. If the prescribed procedure doesn't say anything specific about logical requirements then legal norms can exist (which means that they are valid-as von Wright assumes too from the very beginning) without being consistent.
} 


\subsection{Conclusions}

What we get in this way is a formal representation of the Hohfeldian system where we provide a uniform formalization of rights and duties, maintaining in the Hohfeldian intentions (according to which they are sui generis, that is, not reducing them to something else), assigning to the formal traditions of classical approaches, still, saying something more comprehensive about how a system of rights and duties work (together with actions). What we build on is the relationality of the Hohfeldian right conceptions, the state enforcement, and the right-changing potential of Power.

\section{Rūta Liepiņa: modelling causation in evidence-based legal reasoning}

This research project aims to develop a framework for modelling and reasoning about causal and evidential links in cases. This paper presents motivations and background of the study in legal causation. It sets out the research agenda and presents preliminary results of modelling causal and evidential arguments using a semi-formal framework that employs defeasible logic and introduces basic notions of causal relations.

Causation plays an important role in legal reasoning and decision making. This study is inspired by both theoretical and practical considerations. Causation remains a complex and controversial topic in science and law with many theories focusing on different aspects of causality. Our focus is on the practical implications of understanding and analysing causality, and so the selection of the approaches is limited to those that have some potential impact in the law. Two central points of interest in our research are: (1) how to use formal theories of causation to improve clarity of the requirements for successfully establishing causal links in cases; and (2) how to support legal reasoners in deciding between alternative causal explanations. Moreover, we are also interested in the aspects of causal language that enables identification of causal links in the cases.

This work aims to help to bridge the gap between practical and theoretical approaches to causation by providing a better understanding of causation in law and creating an integrated framework for analysing legal reasoning. It

- provides comprehensive analysis that aims to improve the understanding of legal causation in legal cases;

- provides new insights in causal reasoning in law through an evidential reasoning framework;

- considers already established formal approaches to find new practical applications in law.

The proposed approach to analysing law provides original outcomes due to the focus on a core aspect of legal reasoning that has not yet been formally developed in law. 
This section will present the research questions, background of the relevant fields, problem identification, and preliminary results of my doctoral project focusing on causal issues in the law. ${ }^{15}$

\subsection{Research questions}

There are three key processes of causation in law that we are interested in: identification, modelling, and reasoning. In addition, we are interested in the role of evidence in legal reasoning and how it interacts with causal links in cases. To investigate these areas, we have set the following research questions:

Q1 How to design a method of consistently moving from causal links in legal texts to abstract reasoning models?

(a) How to identify causal and accompanying hedging expressions in legal texts using linguistic tools?

(b) How to abstract from the causal language to semi-formal models in a systematic manner? Can such process be automated?

Q2 How to model causal relations in cases?

(a) How to adapt existing general causation theories to capture causal relations in legal cases?

(b) In what ways are these models supporting legal reasoners in causal analysis?

Q3 How to reason with causal models in law?

(a) How can formal and semi-formal theories support the choice between alternative causal models in law?

(b) What is the role of evidence in legal reasoning and how can we integrate reasoning from evidence in the causal models?

(c) How to bridge the gap between formal theories of causation and evidence, and the needs of legal practitioners?

\subsection{State of art}

Due to the formal and practical background of this project, it requires an interdisciplinary approach. The state of art of causation has its roots in various fields including formal logic and computational theories (Halpern and Hitchcock 2014; Bochman and Lifschitz 2015, language studies (Solan and Darley 2001; Pinker

\footnotetext{
15 Rūta Liepina is a Ph.D. Candidate in Law at the European University Institute, Florence and is supervised by Giovanni Sartor, European University Institute and Adam Wyner, University of Aberdeen.
} 
2007), philosophy (Pearl 2009; Halpern 2008; Halpern and Hitchcock 2010) and law (Hart and Honoré 1985; Honoré 2010; Wright 2011). Evidential reasoning relates to several fields, e.g. logic and law, evidence (Wigmore 1937; Anderson et al. 2005), and argumentation in artificial intelligence (Lehmann et al. 2004; Dung 1995; Walton 2005; Mueller 2014). This section will focus on the fundamentals of these fields of research in relation to the study of causal and evidential reasoning in law.

\subsubsection{Formal theories of causation}

Causation is an important and challenging research topic in most branches of science. The focus of this work is on the formal theories of causation that have potential application in law. In particular, after surveying the relevant literature, we have chosen to focus on two dominant theories of causation-NESS by Hart and Honoré (1985), later developed by Wright (2011) and 'actual causation' by Halpern and Hitchcock (2010). These theories help our analysis on two levels. Firstly, they provide alternative ways of identifying and modelling causal links. And, secondly, these theories propose criteria for comparing alternative causal explanations. Importantly, authors have identified these theories as applicable in legal scenarios (Wright 2011; Halpern and Hitchcock 2014).

NESS presents a more restricted version of the existing counterfactual approaches in the law (e.g., sine qua non: but for the action, the result would not have happened) based on the conditionality of necessary and sufficient conditions (Hart and Honoré 1985; Wright 2011; Lehmann et al. 2004). NESS describes a causally relevant condition as a necessary element of a set of conditions jointly sufficient for the harmful outcome (Honore 2010). The idea can be attributed to J.S.Mill, and has been further developed by Hart and Honoré, and advanced for more complex causal issues by Wright (2011). NESS approach appeals to the idea of generalisations about causal relations (Honoré 2010) where causal models would be based on instantiations of such generalisations to compare alternative causal models. Law presents further complications with establishing the connection between the cause and effect as well as attributing legal responsibility that are due to the complex nature of shared responsibility and proving causal links over time.

The second approach of interest is the actual causation theory by Halpern and Hitchcock (2010). What distinguishes this approach from others is the method of modelling causal relations. Halpern and Pearl try to avoid the ambiguity in determining the cause and effect by using a formal approach of structural equations. Actual causation can model more complex causal relations and is a good competitor with the NESS test. Furthermore, Halpern and Hitchock have developed an extension of the theory that allows for alternative causal explanations to be compared (Halpern and Hitchcock 2010), based on the notions of normality, defaults and typicality. The idea behind this extension is to compare the alternative causal explanations based on the closeness to what has been defined as the normal state of the relevant events. For instance, when multiple agents could have prevented a harmful event, causal responsibility could be attributed to the omission of the agent who had the obligation to prevent it. The authors claim that it can be 
based on various criteria, including statistical data, moral norms, and prescribed norms. The latter are especially relevant to considerations in law.

Both of these theories provide additional tools for analysing causation in law. An alternative theory to causation that provides some relevant insights is the approach from the field of the logic of action, in particular, the STIT theory of causation ('sees to it that') (Segerberg et al. 2016), however, it will not be considered in this work.

\subsubsection{Language of causation}

Law as a highly textual field is often analysed through linguistic methods. The aspects of causal analysis are no exception. One of the dominant approaches in the field of law and causation has been proposed by Solan and Darley (2001) and Tiersma and Solan (2012) in his study on the links between language and liability attribution. Other linguistic properties of causal expressions have been explained by Pinker (2007). Similar ideas of common sense reasoning in causation are in accord with the works of Hart and Honoré (1985).

In order to identify causal links in cases, we wish to consider the current developments of the law and language research in causality (Mueller 2014). We are especially interested in the ideas and tools on automated processes of identification and abstraction from legal texts to semi-formal models. For that purpose, we intend to test Verbnet (Elson and McKeown 2009) verb properties, which can be later used to tag language in text using GATE (Cunningham et al. 2002) allowing for some of the abstraction to be computed.

\subsubsection{Evidential approaches and causation}

With the increasing complexity of evidence presented at courts, evidential reasoning approaches provide useful insights into legal reasoning from various perspectives (Verheij et al. 2015). The three most prominent approaches in this field of research are the argumentative (Verheij 2003; Walton 2005; Wigmore 1937; Prakken 1993), scenario based (Pennington and Hastie 1993; Bex and Bench-Capon 2017; Bex et al. 2010), and probabilistic (Fenton et al. 2016; Fenton and Neil 2011; Chockler 2015). Each of them provides its own advantages of understanding the mind and actions of legal reasoners. For instance, the scenario based approach appeals to cases with a clear narrative of events and emphasises the use of scenarios in human reasoning. It provides an overview of the case with a coherent story of events, exposing missing links and human biases. All the approaches aim not only to provide a better understanding of evidence based legal reasoning, but also draw inspiration from the limitations of human reasoners and propose ways reasoning could be improved. Furthermore, there have been attempts of various combinations among these approaches to provide a more comprehensive account of one's reasoning in specific domains (Bex 2015; Vlek et al. 2014; Timmer et al. 2014). Causal analyses in these studies are at their early stages but have the potential of augmenting the various theories of evidential reasoning. We intend to draw 
inspiration from these approaches to integrate a level of evidential reasoning in the analytical framework dealing with causal links in cases.

\subsection{Problem identification}

This study focuses on two levels of complexity that are relevant to legal reasoning and decision making: the parties have to develop arguments to establish cause-infact, and the legal decision-makers have to balance such arguments to attribute legal responsibility. This study has been inspired by the issues identified by the US Vaccine Injury Court. In particular, in the Althen's decision, ${ }^{16}$ the Special Master identified that the criterion for establishing a satisfactory causal connection is 'an unresolved legal issue'; and moreover, the Special Master emphasised that 'without articulate standards providing guidance [on causation], the experts bring their own beliefs and biases into the courtroom'.

On a more theoretical level, legal reasoning encompasses various aspects of causation. Besides causation-in-fact, law also considers evidence, norms, precedents, expert witness testimonies, and other variables relevant to causal analysis. Existing formal theories of causation are not directly applicable to law due to the highly technical features of the theories and simplified understanding of legal causation. There have been attempts to combine various formal approaches to analyse legal cases (Bex 2015; Halpern and Hitchcock 2010), but there still remains a gap between formal theories of causation and the practical needs of causal analysis in law. In particular, it can be observed that there are significant discrepancies between the legal and formal approaches because of the limited guidelines given for the legal causal analysis and the complicated, technical subject matter. However, so far solutions have not yet been proposed in terms of causation. Due to the significant impact of causal analysis in legal liability attribution, it is important to develop and apply current approaches with an aim of increasing clarity and reducing uncertainty in legal reasoning.

\subsection{Methodology}

While there are many interdisciplinary approaches to legal analysis, there is no dominant methodology underlying the investigations of causal reasoning in law. As identified above, one of the aims of this study is to bridge formal theories of causation with the practical needs of legal reasoners, and so our methodology reflects this strategy. We, first, limited the scope by choosing the causal aspects relevant to law: identification of causal links, modelling causal relations, the use of evidence to reason with causal links, ways of comparing alternative models, and meta-level reasoning about causation in decision making and legal responsibility attribution. And, second, we surveyed the formal theories and assessed their suitability for analysing these aspects. Third, we are working on adapting these theories for the use in cases through our analytical framework, based on defeasible logic and basic causal notions.

\footnotetext{
${ }^{16}$ Althen v Secretary of HHS, 418 F.3d 1274, (3 June 2003, Office of Special Masters, Golkiewicz).
} 
In particular, we employ the ideas of Solan and Darley (2001), Talmy (1988) and Pinker (2007) for designing a method for identifying causal and hedging expressions in legal texts. We also plan to investigate some of the already available tools supporting causal language (VerbNet, GATE) (Girju 2003). For causal link modelling, we focus on two theories of general causation-NESS by Wright (1985) and 'actual causation' by Halpern and Hitchcock (2010). These theories are helpful on two levels. Firstly, they provide ideas on how to model causal links, and, second, they set out some criteria for comparing alternative causal explanations. Both of these considerations tie in with the overall aim of this research-improving understanding of causation and supporting legal reasoners in causal analysis. In order to incorporate ideas from legal practice, case scenarios from existing case law of vaccine injury court were used to evaluate and illustrate causal models in law. This exercise required a development of a method for abstracting causally relevant links in real cases and then a way of modelling them in terms of strict and defeasible rules (Prakken 2008). We build the framework based on an intuitive understanding of causal links as presented by the parties in the case.

\subsection{Preliminary ideas and contributions to the field}

\subsubsection{Preliminary results}

At this stage, we have completed the groundwork of the study by selecting the relevant formal theories of causation and adapted them for the purposes of modelling and reasoning about causation in law. For the evidential reasoning level, we have surveyed the story-based, argumentation and probabilistic theories to determine their approach to causation and possible paths for integrating them in our framework.

Semi-formal framework Our semi-formal framework for causal analysis is a propositional language for various basic facts/events and for various causal relations between them, which can be used to express different degrees of belief in the strength of the causation. The causal relations are based on the causal language of the reasoners, and at this point, we give no formal definition for them. It is important to emphasise that what is being modelled are the concepts sufficient to causal reasoning in legal cases and not causal reasoning per se. The model based on this language provides the reasoning rules that are used to reason with the propositions. The framework also accommodates abductive reasoning of the evidential reasoning based on the causal relations. The important point is that the analysis is able to accommodate the causal relations that are presented as the core disagreements between the parties and shed some light on the structure of the arguments provided by the expert witnesses. Other matters are out of scope at this moment, in particular, the dynamics of dialogue or belief change. Rather, it is a static model that lays out all the information available. To test the framework we applied it to the vaccine injury case and focused on the medical expert witness testimonies as the source of causal disagreement. Our models make explicit some of the otherwise implicit assumptions that are highlighted in the course of the presentation of the expert 
testimony and by way of attack. The preliminary results of using the semi-formal framework show that it provides an intuitive way of modelling causal links in law.

Linguistic analysis For linguistic analysis of causal relations, we employed a bottom-up approach and started by analysing the language of the Althen case. The preliminary analysis has been done by manually identifying and annotating causal expressions in Althen case. We focused on identifying general and legal causal expressions, and finding the accompanying probabilistic expressions to show different strengths of belief by the reasoners. We then chose opposing arguments for the causal links in the case and abstracted from the original text to model these relations in our semi-formal framework.

\subsubsection{Research agenda}

Based on these results, we have planned the next stages of analysis to progress towards a framework that supports legal reasoners in modelling and reasoning about causation. These are subject to change.

(a) Building a method for expressing identification and abstraction It is common for formalists to abstract from legal sources to formal models. However, there is no agreed methodology on how it can and should be done. It raises issues of justification of the concrete models and problems with reproducing the experiments and case studies. Our investigation is focused on causal expressions in legal texts. Next steps in our analysis involves testing existing annotation tools (VerbNet, GATE) to see whether they are able to pick out the causal expressions that we have manually identified in our case study. The research goal is to advance the current state of art in abstracting from legal texts for the purposes of formal modelling.

(b) Further development and integration of the semi-formal causal framework The current framework is able to model and analyse simple causal issues presented through complex arguments. Further developments of the framework involve accommodating more complex causal issues, such over-determination of causes, pre-emption and omission, while fine-tuning the structure of the framework. We are also yet to define the inferences that can be drawn from the evidence linked to causal relations. These will be tested with a set of vaccine injury cases to see whether additional insights can be produced. To put our framework in the context with other approaches to causation, we compare the causal models produced with NESS and actual causation reasoning models.

(c) Defining preference relations between alternative causal models After the framework is developed to a stage where causal links can be successfully modelled, there is a need to define the criteria for weighting alternative causal explanations. Such a process is common in legal decision making. Our aim is to show how some of the balancing can be done through formal approaches. We will propose a set of criteria for choosing between the models, and compare those with the following three approaches to balancing arguments: generalisation model (Wright 1985); normality, typicality and default model (Halpern 2008); and probabilistic model (Chockler 2015). Comparison among these models should show the advantages and disadvantages of employing adapted formal theories in law. 
(d) Bridging the gap As the last stage of investigation in causation in law, we want to bring the discussion back to legal matters, and compare the formal reasoning models with the practical reasoning of judges and how formalism can aid in decision making. Tort law has been chosen as the area of interest due to the indepth discussions about causal issues both in theory and practice (Wright 1985). It is important to distinguish the processes of legal reasoning that can have formal representation, and those that will depend on legal concepts (such as fairness, public interest, and others), and position our work in the relevant areas where support can be provided.

\subsubsection{Contributions to the field}

The main contribution of this work is in the fields of causation and legal reasoning. Our approach aims to improve the current understanding of causal links in cases by modelling and providing criteria for reasoning with these models. The contribution has both theoretical and practical value. This study provides new insights on how to use existing formal theories of causation in law with considerations to the complexity of legal cases. On a practical level, our analysis provides ways of clarifying the current guidelines of causal reasoning in the selected areas of law. Moreover, we consider the role of evidence in legal decision making associated with causal links and burden of proof in the vaccine injury cases. We aim to integrate a level of evidential considerations in our framework.

Our work also contributes to the field of artificial intelligence and law by proposing a method on identifying causal language and abstracting from legal texts to build formal models. Our proposal is based on using already developed theories and tools, and amending them for the needs of legal analysis.

Lastly, the overarching goal of this research is to bring formal and legal theories closer for the joint aim of improving the analysis of causal links in cases. As an interdisciplinary research, this work aims to provide new insights in law from 'external' viewpoint and show practical applications of the formalisms. A set of US vaccine injury case studies is used to validate the value of these approaches. ${ }^{17}$

\section{Mirna El Ghosh: automation of legal reasoning and decision based on ontologies}

\subsection{Research question}

Our research ${ }^{18}$ analyses the problem of building a well-founded legal domain ontology for (rule-based) legal reasoning and decision support systems. Legal

\footnotetext{
17 Rūta Liepina would like to thank her supervisors, Prof. Giovanni Sartor and Dr. Adam Wyner, for the ongoing support and encouragement in the endeavour of understanding and untangling casual and evidential issues in law. This work presents the current state of her Ph.D. project at the European University Institute.

18 Mirna El Ghosh is a Ph.D. student at LITIS, INSA du Rouen, under the supervision of Habib Abdulrab, INSA du Rouen, Hala Naja and Mohamad Khalil, Lebanese University.
} 
decision support systems, known as legal knowledge based systems (LKBS), are capable of legal reasoning, since they are based on a model that describe the norms operating in the legal system. There are three main models for legal reasoning: rulebased (Sergot et al. 1986), case-based (Ashley 1991) and hybrid (Skalak and Rissland 1992). For the current research, the scope is limited to rule-based legal reasoning. Generally, rule-based reasoning models are composed of two main parts: rule-based domain knowledge and a reasoning engine (Buchanan and Shortliffe 1984). We aim to develop a simple, but expressive, domain knowledge base in order to produce useful reasoning. It is desirable to use legal domain ontologies for developing such domain knowledge (Van Kralingen et al. 1999). They are used mainly for modeling the legal norms of the given legal domain.

Generally, building ontologies from scratch is not an easy task. It is considered as a resource-intensive, time consuming and costly task. This is due to the difficulty and complexity of capturing knowledge from legal sources which are mainly unstructured textual documents such as legislations and codes which often require interpretation by an expert. In this regard, in order to reduce the complexity of building legal domain ontologies, a modular middle-out approach is proposed. This approach tends to simplify the ontology building process based on reusing existent foundational and legal-core ontologies in a top-down strategy and on an ontology learning process in a bottom-up strategy. Both strategies will be integrated to obtain the resulting global ontology. In order to complete the domain knowledge of the rule-based legal reasoning model, a set of logic rules will be constructed based on the obtained legal domain ontology. In this context, an integration process will take place to combine the ontology and the rules. The domain application of this research is the Lebanese criminal system and the Lebanese criminal code is considered as the main textual resource since it contains the legal norms of the Lebanese criminal domain.

\subsection{Challenges}

In this research, there are two main challenges concerning the building of the criminal decision support system mainly for the reasoning model components: building a well-founded legal domain ontology for modeling the legal norms of the criminal domain and formalizing the logic rules of the legal reasoning model of the decision support system based on the resulting ontology.

It is commonly known that ontologies aim to capture consensual knowledge of a given domain in a generic and formal way, to be reused and shared across applications and by groups of people (Corcho et al. 2007). Meanwhile, it can be seen from the literature that the number of ontologies has increased and they are becoming larger and more complex to manage and reuse (d'Aquin et al. 2007). For the purposes of our research, the challenge that we face is to build well-founded ontology for modeling the norms of the criminal domain using modularization techniques as an ontology engineering principle. Ontology modularization and the problem of formally characterizing a modular representation for ontologies are great challenges in the ontological engineering domain. 
Furthermore, based on the legal domain ontology, there is a need to formalize the legal norms of the criminal domain. In this context, the challenges to be faced are how to integrate the obtained ontology with logic rules. The integration of ontologies and rules remains a challenging task in the knowledge engineering domain for building rule-based reasoning models.

\subsection{State of the art}

Our research is composed of two main parts: building the criminal domain ontology and constructing the legal reasoning model of the rule-based decision support system based on this ontology.

Concerning the ontology building process, two main categories of approaches exist in the literature: top-down and bottom-up (d'Aquin et al. 2007). The bottom-up approaches start from the most specific concepts and build a structure by generalization (Ashley and Rissland 1987) where the building process of the ontology usually starts with linguistic study of existing data structures forms (documents, reports, etc.) in order to extract relevant concepts of the domain and relations among them with the semi-automatic support of document analysis tools. Top-down approaches start from the most generic concept and build a structure by specialization (Gandon 2002). In this approach, the building process of the ontology starts by an analysis and study of relevant information sources about the given domain and then modeling the top level concepts which will then be refined in a series of further steps.

Meanwhile, for the construction of the legal rule-based reasoning model, two main approaches are found in the literature for integrating ontologies and rules: homogeneous and hybrid (Antoniou et al. 2005). The homogeneous approaches define the integration between ontologies and rules over a tight semantic integration where ontologies and rules are embedded in a common logical language. The most typical homogeneous paradigms are: Combination of OWL ontologies with SWRL $^{19}$ rules (Antoniou et al. 2005) expressed in First Order Logic (FOL) and Description Logic programs (DLP) (Grosof et al. 2003). In contrast, the hybrid approaches define the integration between ontologies and rules over a strict semantic separation where the ontology elements and the rules predicates are separated. In this strategy, rules are expressed in Logic Programming LP formalism. The most typical hybrid approaches are Answer Set programming (ASP) (Gelfond and Lifschitz 1991), dl-programs (Eiter et al. 2008) and DL+log (Rosati et al. 2006).

\subsection{Proposed approaches}

In our research we have proposed two main approaches: a modular middle-out approach for building the criminal domain ontology and a homogeneous approach for integrating the resulting ontology with the logic rules in order to form the legal reasoning model of the legal decision support system.

\footnotetext{
19 https://www.w3.org/Submission/SWRL/.
} 


\subsubsection{Modular middle-out approach for building criminal domain ontology}

A modular middle-out approach has been proposed for building a criminal modular domain ontology (Ghosh et al. 2016). The proposed approach tends to combine two complementary strategies: top-down and bottom-up. In the ontology building process the modularization techniques are used to split the ontology into four independent modules (upper, core, domain and domain-specific), which are themselves ontologies, capable of reuse. At the highest level, the upper module represents the most general concepts and relations that cover all the domains. The core module provides a definition of structural knowledge in the legal domain. The domain module, in turn, describes the conceptualization of the criminal domain. Finally, at the lowest level, the domain-specific module describes the most-specific knowledge of the Lebanese criminal domain.

Concerning the strategies: top-down consists of the definition of the highest part of the conceptual structure of the criminal domain which is modeled as ontology modules (upper and core). In this strategy, reusing existent ontologies, that capture similar or complementary knowledge (foundational and core-legal ontologies such as UFO (Guizzardi 2005), LKIF-Core (Hoekstra et al. 2007; Hoekstra 2000) can help in building a well-founded ontology. Meanwhile, the bottom-up strategy consists of extracting the legal concepts and relations among them from textual resources (the Lebanese criminal code) by using Ontology Learning and NLP techniques and then modeling this knowledge as domain and domain-specific modules. Eventually, the resulting ontologies are combined to form the complete architecture of the criminal domain ontology.

\subsubsection{Homogeneous approach for ontology and rules integration}

In order to build the legal reasoning model for the legal decision support system, there is a need to integrate the resulting criminal domain ontology with a set of logic rules. For this purpose, an ontology-based homogeneous approach is proposed to define a tight semantic integration where the ontology and the rules are embedded in a common logical language. In this approach, the ontologies are treated as an external sources of information accessed by rules. Ontology concepts and properties may be defined through the rules. The most typical homogeneous paradigm is the combination of OWL ontology with SWRL rules expressed in First Order Logic (FOL) (Antoniou et al. 2005).

\subsection{Results}

In this section, we will discuss briefly the results obtained for the proposed approaches concerning the criminal modular domain ontology and the rule-base of the legal reasoning model. 
Fig. 1 Middle-out approach for building CriMOnto

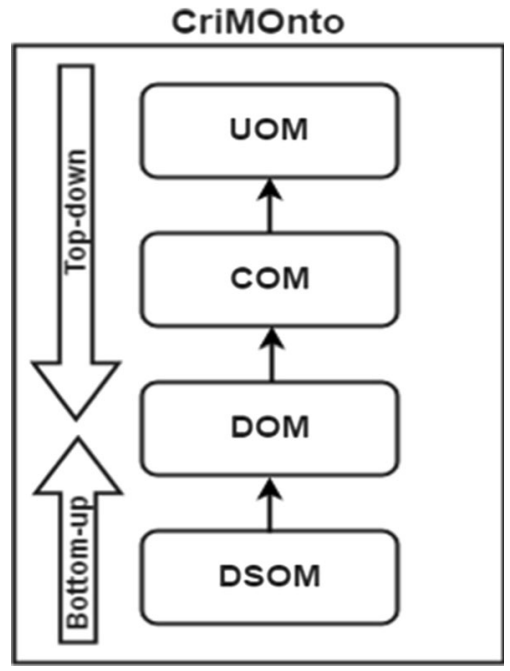

\subsubsection{Criminal modular domain ontology}

After applying the proposed middle-out approach, a criminal modular domain ontology, named CriMOnto is obtained. The proposed approach is defined by developing the modules independently and then combining them together to compose the whole CriMOnto (see Fig. 1) (Ghosh et al. 2016). From this perspective, the different modules can be considered different subjects since they are at different conceptual levels. Therefore, an integration process is performed to combine them (Bontas et al. 2005).

Upper ontology module The UOM consists of abstract concepts and relations which are effectively independent of any specific domain (see Fig. 2). For a principled development of this module, the unified foundational ontology UFO, proposed by Guizzardi and Wagner (2010), is partially reused to facilitate and speed up the ontology development process by avoiding reinvention of the wheel concerning basic categories (Rosa et al. 2012). Therefore, UFO permits the building of an ontology reusing some generic concepts such as Category, Kind, Subkind, Relator, Role, Role_Mixin and Event, where the ontologist does not need to rebuild these concepts. In order to make possible the activity of conceptual modeling via UFO, a conceptual modeling language, named OntoUML (Guerson et al. 2015), is used. OntoUML uses the ontological constraints of UFO as modeling primitives and is specified above the UML 2.0 meta-model. ${ }^{20}$

Core ontology module The COM consists of concepts and relations that are common across the domains of law and can provide the basis for specialization into domain and domain-specific concepts. The same perspective is applied, as for the upper module, for reusing partially the legal core ontology, LKIF-Core, ${ }^{21}$ to build this module (see Fig. 3).

\footnotetext{
${ }^{20}$ http://code.google.com/p/ontouml-lightweight-editor/, last accessed 19/4/2017.

21 https://github.com/RinkeHoekstra/lkif-core.
} 


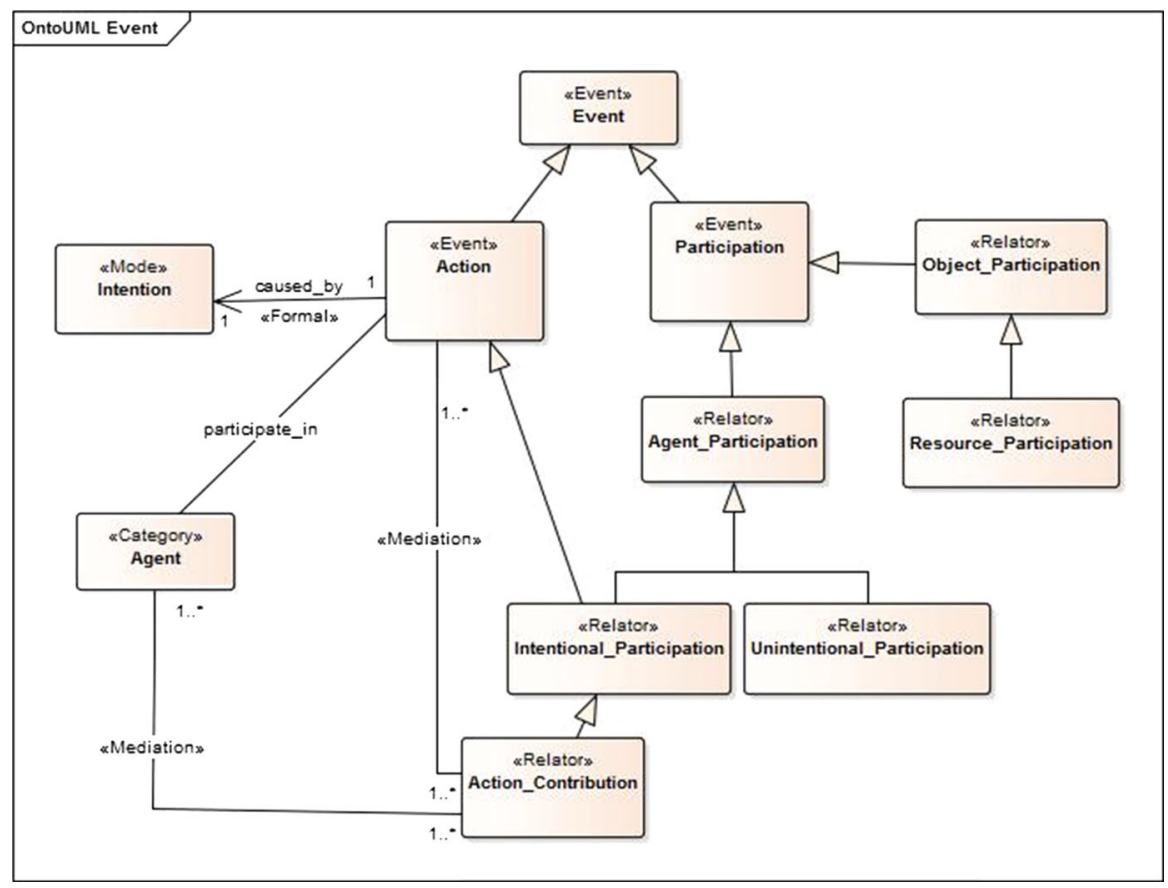

Fig. 2 Fragment of the upper module in OntoUML

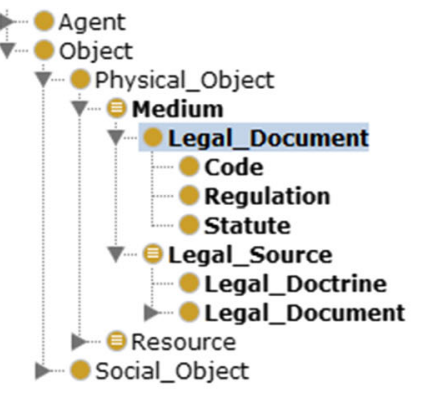

Fig. 3 Excerpt of the Core Module in Protégé

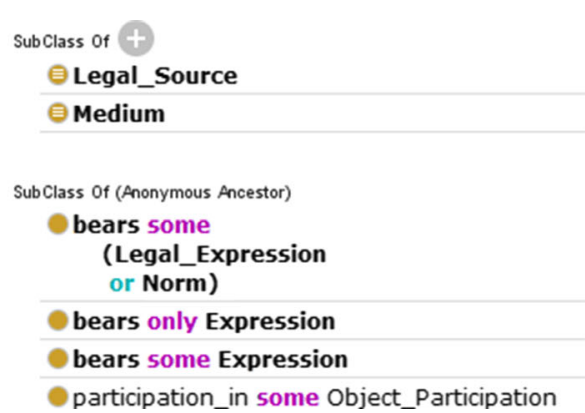

Domain ontology module The DOM is composed of categories that are related mainly to the criminal domain in general such as Criminal_Act, Penalty, Misdemeanor, Violation, etc. In order to build this module, two main strategies are applied: (1) specialize the concepts and relations of the core module (Fig. 4a); (2) extract the knowledge from textual resources using ontology learning and NLP techniques (El Ghosh et al. 2017) (Fig. 4b).

Domain-specific ontology module The DSOM consists of concepts and relations of a specific subject domain such as the Lebanese criminal system (see Fig. 5). The bottom-up strategy helped to generate semi-automatically the domain-specific ontology. Unfortunately, the generated results were inexpressive and thus 
(a)

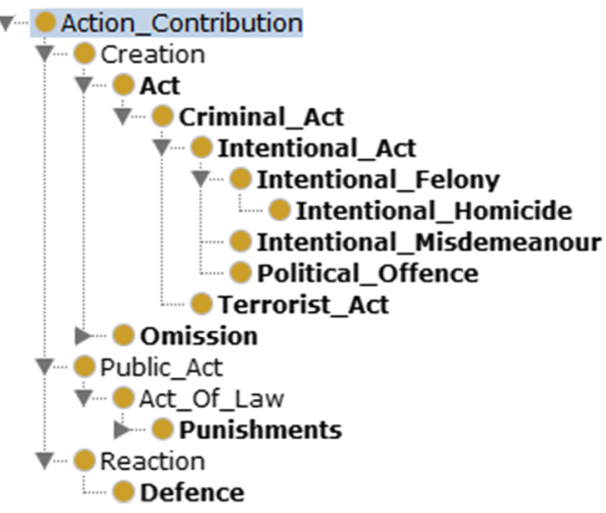

(b)

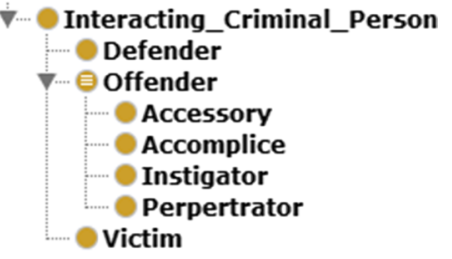

Fig. 4 Excerpt of the Domain Module in Protégé

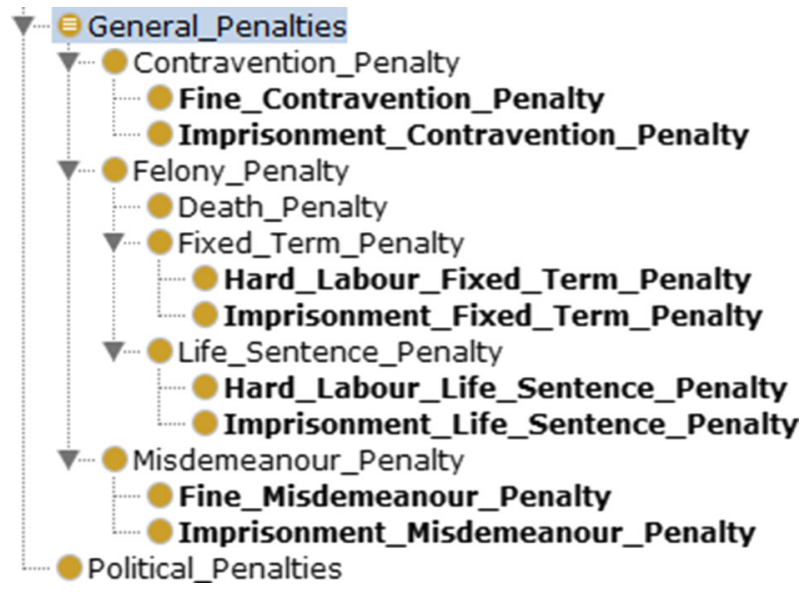

Fig. 5 Excerpt of the Domain-specific Module in Protégé

Fig. 6 Hierarchical Mapping in Protégé

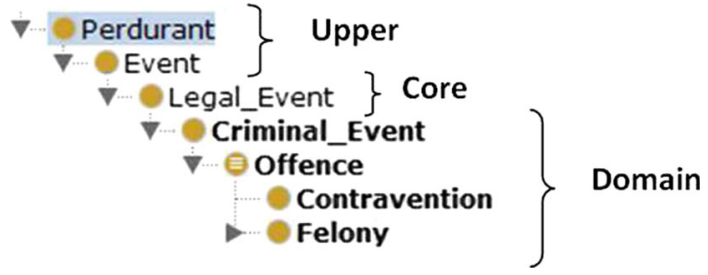

insufficient for practical use. For this reason, a re-engineering process, inspired by the work of Caldarola et al. (2015), was applied to correct, prune and enrich the extracted ontology and make it more expressive by transforming it to heavyweight or axiom-based ontology. 
Integration process of ontology modules The integration phase is the final step after building the independent ontology modules to form the resulting ontology CriMOnto. The source ontologies or modules (upper, core, domain and domainspecific) are combined and assembled together. In this context, a simple vertical mapping strategy is applied between the concepts of the different modules. In our experiments, since ontology modules are located on vertical conceptual levels from general (upper module) to specific (domain-specific module), the mappings will be based mainly on a parent-child hierarchical relationship (Legat et al. 2014). Finally, all the modules are imported into the final ontology using the OWL:imports formalisms (see Fig. 6).

\subsubsection{Rule-base of the legal reasoning model}

The Rule base of the legal reasoning model of the decision support system stores the knowledge in form of rules. In the legal domain, a legal norm is represented by an obligation rule that denotes that the conclusion of the rule will be treated as an obligation in the following form:

\section{IF condition (operativefacts) THEN conclusion (legal effect).}

For representing the norms of the Lebanese criminal code, a modeling process is needed, as well as a rule language. The modeling process is based on a homogeneous integration of the obtained criminal domain ontology and SWRL selected as a rule language. In SWRL, rules are of the form of an implication between an antecedent (body) conjunction and a consequent (head) conjunction in the following form (Antoniou et al. 2005):

Table 1 Legal norms and rules expressed in SWRL

\begin{tabular}{|c|c|c|}
\hline $\begin{array}{c}\text { Article } \\
547\end{array}$ & $\begin{array}{l}\text { Anyone who intentionally kills another } \\
\text { person shall be punishable by hard labour } \\
\text { for a term of between } 15 \text { and } 20 \text { years }\end{array}$ & $\begin{array}{l}\text { Intentional_Homicide(killing), } \\
\text { committed_towards(killing,?y), } \\
\text { committed_by(killing, ?x) } \\
\Rightarrow \\
\text { is_punished_by(?x, hard_labour), } \\
\text { imposed_for_maximum(hard_labour,max_d_2), } \\
\text { imposed_for_minimum(hard_labour, min_d_2), } \\
\text { term_value(max_d_2, 20), } \\
\text { term_value(min_d_2, 15), } \\
\text { term_type(max_d_2,“years”), } \\
\text { term_type(min_d_2, “years”) }\end{array}$ \\
\hline $\begin{array}{c}\text { Article } \\
213\end{array}$ & $\begin{array}{l}\text { An accomplice to an offence shall be liable } \\
\text { to the penalty prescribed by law for the } \\
\text { offence }\end{array}$ & $\begin{array}{l}\text { Accomplice }(? \mathrm{x}) \\
\text { commit }(? \mathrm{x}, ? \mathrm{y}), \\
\text { is_punishable_by }(? \mathrm{y}, ? \mathrm{z}) \\
\Rightarrow \\
\text { is_liable_to_punished_by }(? \mathrm{x}, ? \mathrm{z})\end{array}$ \\
\hline
\end{tabular}




$$
\mathrm{a}_{1} \wedge \mathrm{a}_{2} \wedge \cdots \mathrm{a}_{n} \Rightarrow \mathrm{b}_{1} \wedge \mathrm{b}_{2} \wedge \cdots \mathrm{b}_{n}
$$

By representing legal norms using SWRL, we assume that they are conflict free and will be complied with. In Table 1, we give two examples of SWRL rules, expressed using CriMOnto elements. ${ }^{22}$

\section{Robert van Doesburg: FLINT, a formal method for the interpretation of sources of norms}

This research investigates a standardized method for expressing the interpretation of sources of norms in natural language in a formal representation. The representation formalism is machine readable and our method results in executable expressions. We developed a domain specific language (DSL), called FLINT (Formal Language for the INTerpretation of sources of norms). In this section, we give an overview of the foundations of FLINT and explain the value of FLINT compared to existing methods for legal knowledge engineering.

Major concerns of the field of Artificial Intelligence (AI) and Law include legal knowledge acquisition and the use of that knowledge by agents to achieve goals. To be able to perform in this field, agents need knowledge of the semantics of sources of norms that are supposed to regulate their actions. In order to have a computational set of norms, the interpretation of sources of norms must result in formal representations that can be used by a reasoner. Because norms are made by humans and, mostly, expressed in (written) natural language, AI and Law is also about the border between essentially human tasks, and tasks that can be performed by non-human agents. In our research, we address that border. ${ }^{23}$

Engineering challenge Create a standardized method for expressing the interpretation of sources of norms in natural language into a formal representation in a machine readable and executable form.

Research questions To meet the engineering challenge, research questions are formulated, some of which are listed below:

1. Why do existing methods for legal engineering pay so little attention to the explicit interpretation of sources of norms?

2. What knowledge should a normative reasoner have to be able to determine the behavioral context of all agents in a regulated system?

3. How can the knowledge needed by a normative reasoner be systematically acquired from sources of norms in natural language?

4. How can we handle differences in the interpretation of sources of norms caused, e.g., by the inherent ambiguity of statements in natural language?

\footnotetext{
22 This work has been supported by the European Union with the European Regional Development Fund (ERDF) under Grant Agreement $\mathrm{n}^{\circ} \mathrm{HN0002134}$ in the project CLASSE 2 ("Les Corridors Logistiques: Application a la Vallée de la Seine et son Environnement”), the Lebanese University and the National Support from the National Council for Scientific Research in Lebanon (CNRS).

23 Robert van Doesburg is a Ph.D. student at the Leibniz Center for Law, University of Amsterdam, under the supervision of Tom van Engers. The research project is part of a research program on largescale normative reasoning at the Leibniz Center of the University of Amsterdam.
} 
In this section, we will focus on the creation of a standardized method for the formal interpretation of sources of norms in natural language. After a short overview of the work that FLINT is founded upon: i.e. the construction of social reality; Hohfeld's fundamental legal concepts; approaches for the acquisition, representation and use of legal knowledge; and argumentation theory, we will give a short presentation of our work on the formal interpretation of sources of norms in natural language. Finally we will discuss the results of our work until now and the work that needs to be done to meet our engineering challenge.

\subsection{On the representation of norms}

\subsubsection{The construction of social reality}

Norms only exist by human agreement. If people do not agree on the meaning of a norm, they cannot all obey it in the same way. Enforcement of a norm presupposes that the enforcers of that norm agree on its meaning. Searle (1995) explores the possibility of a social reality. Can we construct an objective world of money, property, marriage, government, elections, football games, and so on and so forth? In short: is an objective world of norms and law possible?

An objective social reality is, according to Searle, built upon the following foundations:

1. The existence of a real world, an external reality to which facts correspond (Hume 1739; Russell 1912).

2. Brute facts (Anscombe 1958), e.g. there is snow and ice near the summit of Mount Everest.

3. Social facts (Durkheim 1894), e.g. a pack of hyena's attacking a lion.

4. Institutional facts (Austin 1975), e.g., this piece of paper counts as money.

Like external reality, brute facts and social facts exist independently of human representations. Institutional facts, however, cannot exist without human representation. The hyena's will attack the lion without any person making a representation of it, but the concept of money cannot exist without some kind of human interpretation of it. At the same time institutional facts presuppose brute facts in a real world. Without some kind of brute facts there can be no exchange of knowledge of institutional facts between humans. Van Engers and Boer (2011) applied the idea of constructing social reality to the world of norms and law. They addressed the interaction between sources of norms (the brute facts a norm is based upon), the logical representations of the meaning of these sources (the institutional representation derived from the source, i.e. the interpretation of the source), and the application of that interpretation to an individual case, or to a set of cases, using an implementation model (a social reality). The theory of constructing social reality enables us to separately discuss the existence of sources of norms, the interpretation thereof, the social reality where this interpretation is applied, and the mapping of social facts to an institutional reality. This separation of concerns reduces the complexity of the task of creating a formal, computational representation of norms. 


\subsection{Fundamental legal concepts}

Hohfeld introduced his fundamental legal concepts in 1913 (Hohfeld 1917). The motive to introduce these legal concepts was Hohfeld's opinion that one of the greatest hindrances to the clear understanding of legal problems is the explicit or tacit assumption that all legal relations may be reduced to rights and duties. Hohfeld argued this was not the case by describing the ambiguities in the meaning of these concepts and went on to introduce the smallest set of legal conceptions to which, according to him, any and all legal quantities could be reduced. Hohfeld distinguished four types of legal relations:

1. Power/Liability relations;

2. Immunity/Disability relations;

3. Right/Duty relations;

4. Privilege/No-right relations.

Some scholars prefer the term Liberty instead of Privilege and Claim instead of Right. We do too. The Hohfeldian legal conceptions can only exist in pairs and describe relations between two people, each holding one of the rights in a pair.

The Claim/Duty relation describes the situation in which person $x$ has a claim on person $y$ to perform action $A$, and person $y$ having the duty to perform action $A$. The Liberty/No-claim relation describes the situation where that claim and that duty are absent. A Claim/Duty relation can be created or by exercising the power of person $z$ to perform action B. Person $y$ will have a liability as the result of that action. Person $x$ and person $z$ may be the same person. In a normative (or legal) relation person $x$ and person $y$ must be different persons. The Immunity/Disability relation is a relation in which the power of person $z$ to perform action $B$ is absent. Person $z$ has a normative, e.g. legal, disability to perform action $B$.

Hohfeld called the Claim/Duty relation and Privilege/No-claim relation the first order relations. The Power/Liability relation and Immunity/Disability relation are called second order relations, because they can change first order relations. We call the Claim/Duty relation situational, because it describes a situation that will exist forever unless it is terminated by using a Power/Liability relation. A new situation, and thus a new Claim/Duty relation, can only come to existence as a result of performing an action that is part of a Power/Liability relation. This perspective allows for a systemic view on Hohfeldian relations. Immunity/Disability and Liberty/No-claim relations allow us to argue about the existence of Claim/Duty or Power/Liability relations in disputes, e.g. in a court of law.

Hohfeld's fundamental legal concepts have been formalized by several scholars. An example that makes references to a lot of other formalizations is Sartor (2006), see also Sect. 3. A legal philosophical discussion of the nature of rights in relation to the fundamental legal conceptions of Hohfeld, can be found in Wenar (2005). 


\subsection{An engineer's perspective on legal knowledge}

Valente (1995) distinguished three types of approaches for legal knowledge engineering: the rule-based approach, the case-based approach and the logic approach, and argues for a fourth: the modeling approach. The main focus of his work on this modeling approach, is on functional ontologies. Also Van Kralingen (1995) introduced the frame-based approach, which can be seen as an example of such a modeling approach. All of the approaches described by Valente, provide the knowledge engineer with a specific perspective, that comes with an ontological and epistemological framework, on original sources of norms. Below we give a short description of the characteristics of the four approaches.

The rule-based approach The main assumption behind the rule-based approach is that legislation can be represented as production rules, e.g. having the form of if $A$, then $B$ or if $A$, then add $B$. These production rules can be used in two ways in AI and Law: as a model of sources of norms and, when combined with a reasoning engine, as an implementation device. Production rules are a shallow representation device for law, because they do not express important epistemological distinctions in law. According to Valente (1995) the result of this rule-based approach is that a large part of the systems developed are highly pragmatic and ad-hoc. Deficiencies come from the absence of any theoretical foundation and the use of an oversimplified development strategy. Since 1995 there has been some progress on this subject, but the interpretation of sources of norms in natural language remains problematic, see also De Maat et al. (2009) and Wyner et al. (2016). The rule-based approach is suitable for developing executable models of a given set of formalized norms. The approach has no solution for extracting formalized rules from of sources of norms in natural language.

The case-based approach The case-based approach represents laws merely as cases, and uses cased-based reasoning techniques to reason with them. This is done by analogical reasoning, or rather by solving actual problems (cases) by retrieving similar past cases and using aspects of these retrieved cases to solve the case at hand. The classical example of case-based reasoning used in law is HYPO (Ashley 1991; Bench-Capon 2017). The process of case-based reasoning mimics the behavior of trial lawyers in the USA, and has been successfully used to model cases in this context (Valente 1995). While researchers working on the case-based approach have suggested methods to extract legal knowledge from cases, no solution has yet been proposed for the extraction of formal legal knowledge from statute law, regulations and other non case-centered sources of norms.

The logic approach The truth-based, or logic approach, is an important and pervasive approach for Legal Knowledge Engineering. Logic and truth maintenance systems have been the first formalizations that could run on digital computers, thanks to the fundamental work of Shannon (1948). Logic has been used for reasoning (modeling inferences, implementing them and analyzing their computability and complexity), justification (is this reasoning valid?), and representation (domain representation and representing ontological commitments). Logic is also often used in the rule-based and case-based approaches. In the process of interpreting sources of norms in natural language, however, logic has its downsides. 
The most important of these is that domain experts in the legal field are unfamiliar with logical formulas, especially with the complex non-standard approaches that are being used to represent normative systems (Valente 1995). Furthermore, deontic logic exhibits parodoxes arising from the characteristics of the language (Sileno et al. 2017).

The frame-based approach One of the founding fathers of AI, Marvin Minsky, introduced the term frame as a concept essential for knowledge representation.

Van Kralingen (1995) suggested to use a frame-based approach for legal knowledge engineering. He focused on knowledge capture and claims that frames are inherently suited for making interpretations of sources in natural language. How these frames can be used for reasoning was left to a companion thesis by Visser (1995). Van Kralingen explicitly writes in his thesis that he is not paying attention to problems associated with the interpretation of legal knowledge (Van Kralingen 1995), since this was Visser's role in the project. Visser's contribution with respect to the interpretation of sources however, remains limited to a few remarks on the interpretation of vague concepts, e.g. suitable employment. He suggests to consult court decisions to clarify vague concepts, using a method that can be characterized as mapping the vague concept to a multi-dimensional space, and to use a calculation method to decide if an instance fits the category borders. This looks very much like the HYPO model (Ashley 1991), but then only to reason on the semantics of vague terms. We conclude that both Visser and Van Kralingen left underexposed the issue of how to make the transcription of the source of a norm in natural language into a normative frame. Breaux (2009) made his own frame for analyzing of sources of norms, without referring to the work of Van Kralingen. With his approach, Breaux aimed to support knowledge engineers in building legal reasoning systems and consequently named his approach a Frame-Based Requirements Analysis Method. The frame-based approaches of Van Kralingen and Breaux use their frames to assign text fragments from sources of norms to slots in the frames. If a specific frame element cannot be found in a sentence, or set of sentences, then that frame element remains empty. Also, both approaches have the problem that actions do not necessarily result in a state-transition. Van Kralingen's frames allows for actions that lack a final state. These actions are classified as acts of the type state-of-affairs. Breaux' frame-base lacks a slot for a final state or postcondition. We consider it essential that every action results in a next well-defined final state, or postcondition. If the result of a normative action cannot be found explicitly in a source, the source sentence is not considered to contain a valid FLINT act type frame. The only possibility to repair the deficit of the missing result is by making an explicit statement that:

1. the source sentence implies a specific result,

2. the result of the action can be found in a separate sentence which should be interpreted in conjunction with it.

By making these statements explicit, the interpretations are open to be challenged by alternatives. 
Other authors, like De Maat et al. (2009), have used frame-based approaches to capture knowledge from sources of norms using natural language processing (NLP) techniques. In our research, we use a frame-based approach for making an explicit representation of the interpretations of sources of norms.

\subsection{Norms and arguments}

Since different interpretations of sources of norms may lead to arguments as to which interpretation is preferred, we also study how formal models of interpretation can be discussed using formal methods for argumentation. For this we use argument schemes based on Toulmin's model of argumentation (Toulmin 1958). Statements are considered to be claims, based on reasons. If a claim is attacked successfully, the attack will defeat the claim. This type of attack is called a rebuttal. If the relation between a claim and the reasons that support that claim is successfully attacked, that is called a undercutter (Pollock 1987). So, a successful rebuttal results in the claim being false, and a successful undercutter results in uncertainty whether the claim is true or false. Formalization of argument schemes, using tools such as ARAUCARIA (Reed and Rowe 2004) and ArguMed (Van Eemeren et al. 2014), lies outside the scope of this section. Some work has been done on the classification and formalization of argument schemes concerning the problem of statutory interpretation (Walton et al. 2016; Araszkiewicz 2015). Typically the classification of argument schemes concerns the classification of arguments, e.g. arguments from ordinary meaning, arguments of technical meaning, arguments from legal concepts. There are nog classifications of argument schemes aimed for making a type of claim, e.g. interpretation of a norm respectively the application of a norm to a case.

\subsection{A method for the interpretation of sources of norms in natural language}

Our perspective on the interpretation of sources of norms follows from the goals we want to achieve by using these models:

1. To understand the consequences of sources of norms for all addressees.

2. To allow for a discussion on the interpretation of sources of norms expressed in natural language in a precise way.

3. To provide a large-scale applicable method supporting knowledge engineers in translating these sources of norms into a formal, machine readable and executable representation, thus overcoming ambiguity issues of natural language and allowing for IT-support systems for various tasks.

To be able to achieve these goals we aim for a maximum separation of concerns. Therefore, we separate the source of a norm, and the (formal) interpretation of that source. We separate the interpretation of a norm, and the factual representation of a specific case. And we make a separate representation for the mapping of the factual representation of a specific case onto an institutional model consisting of (formal) interpretations of sources of norms. 
Table 2 The FLINT-language framework

\begin{tabular}{lll}
\hline Act type frame & Duty type frame & Fact type frame \\
\hline Action & Description of duty & Fact type \\
Actor & Duty holder & Derivation function \\
Object & Claimant & \\
Recipient & Liable agent & \\
Precondition & Creating act type & \\
Postcondition & Terminating act type & Reference to source(s) \\
Reference to source(s) & Reference to source(s) &
\end{tabular}

For the interpretation of sources of norms we developed the Formal Language for the Interpretation of Normative Theories: FLINT (Van Doesburg et al. 2016a; Van Engers and Van Doesburg 2016). We use FLINT to formally describe institutional reality (Searle 1995). The Power to act is represented as an institutional act type that consist of an action, described in the source(s) of a norm, that an agent is allowed to perform on an object, if a precondition (consisting of institutional fact types connected by Boolean relations) is met. The action has a postcondition consisting of a institutional fact types, act types or duty types that can be either created or terminated. The result of the action is received by an agent holding the agent role recipient. Act types have a functional perspective, meaning that the performance of a given act type under the same conditions, always has the same result.

The actor is the agent holding the Hohfeldian power, the recipient the agent holding the liability. The performance of a institutional act type can create or terminate: a institutional fact type (e.g. a decision on an application creates a decision and terminates the application), an new institutional act type (e.g. an actor having the power to delegate, can delegate his power to another agent), or a institutional duty type (i.e. the duty of a duty holder to perform an institutional act in the future, and the corresponding claim of the claimant on the duty holder).

The precondition can be elaborated by making detailed expressions for separate institutional fact types. By making separate expressions for the details of individual fact types, the question whether a fact is true or not can be answered using first-order logic. The representation of institutional act types as drivers of state transitions from one world, to another, enables the description of consecutive decisions in the same case without using defeasible logic. As a result FLINT expressions can be presented without complicated logical constructions, enabling direct validation by all members of a multidisciplinary team.

The development of FLINT started in a NWO sponsored workshop, ${ }^{24}$ which has led to a continuing collaboration between academics and industry. It consists of a domain specific language (DSL) and a prototype that supports working with this language. For the three frame types of FLINT, see Table 2.

24 Van Doesburg et al. (2016b). 
When you create a formal representation of a source, the first thing you are faced with is the bootstrapping problem: where to start? Different solutions have been proposed in the past, but most authors remain vague about this particular point. Experience in the POWER project (Van Engers et al. 2000) shows that it doesn't necessarily make sense to start with the first sentence of a source and then work your way to the end of it, if only for the fact that the sources are to voluminous, and contain references to equally voluminous additional sources, and so on and so forth. This leads to a task that cannot be completed. We decided to use a more pragmatic, task-oriented, approach.

We suggest the following procedure for making an interpretation model:

1. Decide which task(s) are to be supported.

2. Find an initial set of relevant sources of norms.

3. Identify an initial set of relevant fragments (sentences or constituents thereof) for the $\operatorname{task}(\mathrm{s})$ at hand.

4. Transform relevant fragments into an explicit interpretation model.

5. If necessary, find additional sources and fragments to fill missing information.

6. Make explicit expressions for all assumptions left implicit by the authors of the sources of norms.

The first step of the procedure constitutes a pragmatic starting point. The last two steps are required to make complete all elements of a frame. An institutional act type cannot exist without an action, actor, object, recipient and some kind of postcondition. An act type without any precondition constitutes an absolute power, it describes an act that is allowed regardless of the condition the actor is in. When a frame is not complete, we assume that information needed to act according to the norms, is missing or inappropriately left implicit. If fragments filling this shortcoming, are not found, we assume that the source of norm contains implicit information, and we choose an explicit expression that, we think, fits the meaning of the interpreted sources of norms best. By making the interpretation of a source explicit, the interpretation is opened up for discussion. Arguments for alternative interpretations can be presented and conflicting interpretations can be debated, resulting in consensus or a decision by an arbitrator.

Unfortunately, this comes at the cost of sacrificing completeness as the boundaries of the resulting model are impacted by the chosen task. The interpretation model itself, however, is task independent. In other words, the model may be used for a variety of tasks, although it may still be incomplete. This brings us to the stopping criteria. This will always remain a question open for debate. There may be new questions or tasks that require additional sources of norms to be included. There may be changes in sources of norms that are already in the interpretation model. And of course, there also may appear new interpretations of existing sources of norms.

The goal of making an interpretation is not to create a complete model that results in the correct answer to any question. The goal is to make a model that can be used to reason about a specific set of questions. FLINT is being used to enable experts from the legal, policy and administrative domain to explicitly formulate 
their interpretation of a source of norm, while knowledge engineers can focus on the formal aspects of the expression.

\subsection{Discussion and conclusion}

\subsubsection{What is new?}

The following aspects are considered to be contributions to the field of AI and Law:

1. A first version of a procedure for knowledge engineers to start and stop the process of modeling sources of norms. The authors do not claim completeness of the resulting interpretation model. All interested parties are invited to argue that not all relevant fragments of sources of norms are included, and/or that the interpretation of these fragments should be changed.

2. Separating the interpretation of norms, and application to specific cases (actual or imaginary). Rule-based, case-based, logic based, and the frame-based approaches by Van Kralingen, Visser ${ }^{25}$ and Breaux do not make this distinction. The FLINT approach distinguishes:

(a) the relevant sources of norms that apply to a specific (set of) task(s);

(b) the creation of an interpretation model for a set of sources of norms, consisting of act types, duty types and fact types;

(c) the facts and acts of a specific case;

(d) the mapping of the facts and acts in a specific case onto an interpretation model.

3. The formal interpretation models allow for applying argumentation schemes to structure differences of opinion on the interpretation of norms, and allows us to use such arguments to reason about the correct application of norms to the facts of a case. For this task we use specific argument schemes for the separate parts of the interpretation, i.e. referring to the relevant sources of norms, interpreting the sources of norms in act types and duty types, describing the facts and acts of a specific case, mapping facts and acts in a specific case onto the interpretation model.

All these contributions enhance transparency. They also substantially decrease the complexity of the validation of interpretation models. Our research thus far resulted in:

1. A procedure for making an interpretation model.

2. Frames for institutional act types, institutional duty types, and derivation functions for institutional fact types.

\footnotetext{
25 Visser does some work on the interpretation of vague concepts. In our view this work is about the mapping of facts and acts of a specific case onto the vague concept that appears in statute law. This view is supported by the case-based approach Visser uses for his interpretations.
} 
3. A DSL for the formal interpretation of sources of norms (FLINT) (Van Doesburg et al. 2016a).

4. A prototype for generating a datalog reasoner from a FLINT representation of a simplified example in the tax domain (to be published).

5. Interpretation models for several legal domains, including Dutch immigration policy (Van Doesburg et al. 2016a), tax policy (Van Doesburg and Van Engers 2017), administrative law (Van Doesburg and Van Engers 2017) and the European General Data Protection Regulation (to be published).

6. First experiment with argumentation schemes for the interpretation of sources of norms (Van Doesburg and Van Engers 2017).

\subsubsection{Future work}

Future work will focus on the following subjects:

1. Evaluation of the method and the resulting interpretation models by experts and laymen and experts from the fields of law, policy advising, public administration, knowledge engineers.

2. Elaborating methods for using argument schemes to resolve conflicts on the interpretation of sources of norms.

3. To re-engineer the FLINT solution allowing for large-scale application. This includes the development of tools for modelers and domain experts.

Acknowledgements The participants of the doctoral consortium would like to thank Guido Governatori, Leon van der Torre, Bart Verheij, Enrico Francesconi, and Giovanni Sartor for volunteering as mentors and Trevor Bench-Capon for his constructive comments and editorial efforts while developing their research reports.

Open Access This article is distributed under the terms of the Creative Commons Attribution 4.0 International License (http://creativecommons.org/licenses/by/4.0/), which permits unrestricted use, distribution, and reproduction in any medium, provided you give appropriate credit to the original author(s) and the source, provide a link to the Creative Commons license, and indicate if changes were made.

\section{References}

Aleven V, Ashley KD (1995) Doing things with factors. In: Proceedings of the 5th international conference on artificial intelligence and law, ACM, pp 31-41

Anderson T, Schum D, Twining W (2005) Analysis of evidence. Cambridge University Press, Cambridge Anscombe GEM (1958) On brute facts. Analysis 18(3):69-72

Antoniou G, Damásio CV, Grosof B, Horrocks I, Kifer M, Ma J, et al (2005) Combining rules and ontologies: a survey. Deliverables i3-d3, REWERSE http://rewerse.net/deliverables/m12/i3-d3.pdf. Accessed 1 Dec 2017

Araszkiewicz M (2015) Incorporation of complex doctrinal theories in a model of statutory interpretation: an example of adequate causal link. In: Proceedings of the 15 th international conference on artificial intelligence and law, ACM, pp 161-165 
Ashley KD (1991) Modeling legal arguments: reasoning with cases and hypotheticals. MIT Press, London

Ashley KD, Brüninghaus S (2009) Automatically classifying case texts and predicting outcomes. Artif Intell Law 17(2):125-165

Ashley KD, Rissland EL (1987) But, see, accord: generating blue book citations in hypo. In Proceedings of the 1st international conference on artificial intelligence and law, ACM, pp 67-74

Austin JL (1975) How to do things with words. Clarendon Press, Oxford

Bench-Capon TJM (2017) Hypo's legacy: introduction to the virtual special issue. Artif Intell Law 25(2):205-250

Bex F (2015) An integrated theory of causal stories and evidential arguments. In: Proceedings of the 15th international conference on artificial intelligence and law, ACM, pp 13-22

Bex F, Bench-Capon T (2017) Arguing with stories. In: Olmos P (ed) Narration as argument. Springer, Berlin, pp 31-45

Bex FJ, Van Koppen PJ, Prakken H, Verheij B (2010) A hybrid formal theory of arguments, stories and criminal evidence. Artif Intell Law 18(2):123-152

Bochman A, Lifschitz V (2015) Pearl's causality in a logical setting. In: AAAI, pp 1446-1452

Bontas EP, Mochol, M, Tolksdorf R (2005) Case studies on ontology reuse. In: Proceedings of the 5th international conference on knowledge management

Branting LK (1991) Building explanations from rules and structured cases. Int J Man Mach Stud 34(6):797-837

Breaux TD (2009) Legal requirements acquisition for the specification of legally compliant information systems. North Carolina State University, Raleigh

Brenk A (2014) Elektroniczne postępowanie upominawcze: kilka uwag na temat e-sądu. Krajowa Rada Sądownictwa, Kwartalnik 3, p 11

Buchanan BG, Shortliffe EH et al (1984) Rule-based expert systems, vol 3. Addison-Wesley, Reading

Caldarola EG, Picariello A, Rinaldi AM (2015) An approach to ontology integration for ontology reuse in knowledge based digital ecosystems. In: Proceedings of the 7th international conference on management of computational and collective intelligence in digital ecosystems, ACM, pp 1-8

Chellas BF (1980) Modal logic: an introduction. Cambridge University Press, Cambridge

Chockler H, Fenton N, Keppens J, Lagnado DA (2015) Causal analysis for attributing responsibility in legal cases. In: Proceedings of the 15th international conference on artificial intelligence and law, ACM, pp 33-42

Corcho O, Ferández-López M, Gómez-Pérez A (2007) Ontological engineering: what are ontologies and how can we build them. In: Jorge C (ed) Semantic web services: theory, tools and applications. IGI Global, Hershey, pp 44-70

Cunningham H, Maynard D, Bontcheva K, Tablan V (2002) Gate: an architecture for development of robust HLT applications. In Proceedings of the 40th annual meeting on association for computational linguistics, Association for Computational Linguistics, pp 168-175

d'Aquin M, Schlicht A, Stuckenschmidt H, Sabou M (2007) Ontology modularization for knowledge selection: experiments and evaluations. In: Wagner R, Revell N, Pernul, G (eds) Database and expert systems applications. Springer, Berlin, pp 874-883

De Maat E, Winkels R, Van Engers T (2009) Making sense of legal texts. In: Grewendorf G, Rathert M (eds) Formal linguistics and law. Walter de Gruyter, Berlin, pp 212-225

Dijkstra JJ (2001) Legal knowledge-based systems: the blind leading the sheep? Int Rev Law Comput Technol 15(2):119-128

Dung PM (1995) On the acceptability of arguments and its fundamental role in nonmonotonic reasoning, logic programming and n-person games. Artif Intell 77(2):321-357

Durkheim E (1894) Les règles de la méthode sociologique. Revue Philosophique de la France et de l'Étranger 37:465-498

Eiter T, Ianni G, Lukasiewicz T, Schindlauer R, Tompits H (2008) Combining answer set programming with description logics for the semantic web. Artif Intell 172(12-13):1495-1539

El Ghosh M, Naja H, Abdulrab H, Khalil M (2016) Towards a middle-out approach for building legal domain reference ontology. Int J Knowl Eng 2(3):109-114

El Ghosh M, Naja H, Abdulrab H, Khalil M (2017) Ontology learning process as a bottom-up strategy for building domain-specific ontology from legal texts. ICAART 2:473-480

Elson DK, McKeown KR (2009) A tool for deep semantic encoding of narrative texts. In: Proceedings of the ACL-IJCNLP 2009 software demonstrations. Association for Computational Linguistics, pp 9-12 
Fenton N, Neil M (2011) Avoiding probabilistic reasoning fallacies in legal practice using bayesian networks. Austl J Leg Phil 36:114

Fenton N, Neil M, Berger D (2016) Bayes and the law. Ann Rev Stat Appl 3:51-77

Fitch FB (1967) A revision of hohfeld's theory of legal concepts. Logique et Anal 10(39/40):269-276

Gandon F (2002) Distributed artificial intelligence and knowledge management: ontologies and multiagent systems for a corporate semantic web. Ph.D. thesis, Université Nice Sophia Antipolis

Gelfond M, Lifschitz V (1991) Classical negation in logic programs and disjunctive databases. New Gener Comput 9(3):365-385

Girju R (2003) Automatic detection of causal relations for question answering. In: Proceedings of the ACL 2003 workshop on multilingual summarization and question answering. Association for Computational Linguistics, vol 12, pp 76-83

Góra-Błaszczykowska A (2016) Kodeks postępowania cywilnego. Tom I. Art. 1-729, C.H. Beck, Warszawa

Grosof BN, Horrocks I, Volz R, Decker S (2003) Description logic programs: combining logic programs with description logic. In: Proceedings of the 12th international conference on world wide web, ACM, pp 48-57

Grossi D, Jones A (2013) Constitutive rules and count as conditionals. In: Gabbay D, Horty J, Parent X, Van Der Meyden R, Van Der Torre L (eds) Handbook of deontic logic and normative systems. College Publications, Los Angeles, pp 407-442

Guerson J, Sales TP, Guizzardi G, Almeida JPA (2015) Ontouml lightweight editor: a model-based environment to build, evaluate and implement reference ontologies. In: 2015 IEEE 19th international enterprise distributed object computing workshop (EDOCW), IEEE, pp 144-147

Guizzardi G (2005) Ontological foundations for structural conceptual models. CTIT Centre for Telematics and Information Technology, Enschede

Guizzardi G, Wagner G (2010) Using the unified foundational ontology (UFO) as a foundation for general conceptual modeling languages. In: Poli R, Healy M, Kameas A (eds) Theory and applications of ontology: computer applications. Springer, Berlin, pp 175-196

Halpern JY (2008) Defaults and normality in causal structures. In: Brewka G, Lang J (eds) Principles of knowledge representation and reasoning. AAAI Press, Palo Alto, pp 198-208

Halpern J, Hitchcock C (2010) Actual causation and the art of modelling. In: Dechter R, Geffner H (eds) Heuristics, probability and causality: a tribute to Judea Pearl. College Publications, Los Angeles, pp 383-406

Halpern JY, Hitchcock C (2014) Graded causation and defaults. Br J Philos Sci 66(2):413-457

Hart HLA, Honoré T (1985) Causation in the law. OUP, Oxford

Herrestad H, Krogh C (1995) Obligations directed from bearers to counterparts. In: Proceedings of the 5th international conference on artificial intelligence and law, ACM, pp 210-218

Hoekstra R (2000) Ontology representation: design patterns and ontologies that make sense. IOS Press, Amsterdam

Hoekstra R, Breuker J, Di Bello M, Boer A, et al (2007) The LKIF core ontology of basic legal concepts. In: Proceedings of the workshop on legal ontologies and artificial intelligence techniques, pp 43-63

Hohfeld WN (1917) Fundamental legal conceptions as applied in judicial reasoning. Yale Law J 26(8):710-770

Honoré A (2010) Causation in the law. In: Zalta EN (ed) The stanford encyclopedia of philosophy, winter 2010 edn. Metaphysics Research Lab, Stanford University, Stanford

Hume D (1739) A treatise on human nature. John Noon, London

Jodłowski J, Resich Z, Lapierre J, Misiuk-Jodłowska T, Weitz K (2014) Postępowanie cywilne. Wolters Kluwer, Warszawa

Jones AJ, Sergot M (1996) A formal characterisation of institutionalised power. Logic J IGPL 4(3):427-443

Kanger S (1985) On realization of human rights. Acta Philos Fennica 38:71-78

Kanger S, Kanger H (1966) Rights and parliamentarism. Theoria 32(2):85-115

Kisielewicz A (2011) Sztuczna inteligencja i logika. Podsumowanie przedsięwzięcia naukowego. WNT, Warszawa

Lang W, Wróblewski J, Zawadzki S (1986) Teoria państwa i prawa. Państwowe Wydawnictwo Naukowe, Warszawa

Legat C, Seitz C, Lamparter S, Feldmann S (2014) Semantics to the shop floor: towards ontology modularization and reuse in the automation domain. IFAC Proc 47(3):3444-3449

Lehmann J, Breuker J, Brouwer B (2004) Causation in AI and law. Artif Intell Law 12(4):279-315 
Leszczyński L (2003) Podejmowanie decyzji prawnych: tworzenie i stosowanie prawa. Wyższa Szkoła Zarządzania i Administracji, Zamość

Lindahl L (1995) Stig Kanger's theory of rights. In: Prawitz D, Skyrms B, Westerståhl D (eds) Logic, methodology and philosophy of science IX, Proceedings of the ninth international congress of logic, methodology and philosophy of science. Studies in logic and the foundations of mathematics, vol 134. Elsevier, Amsterdam, pp 889-911

Makinson D (1986) On the formal representation of rights relations. J Philos Logic 15(4):403-425

Markovich R (2015) No match-making but biconditionals: agents and the role of the state in legal relations. In: JURIX, pp 161-164

Markovich R (2016) Agents, roles, and rights. a formal analysis on the hohfeldian conceptions. In: AiML'2016 short presentations, pp 161-164

McCarty LT (1976) Reflections on TAXMAN: an experiment in artificial intelligence and legal reasoning. Harv Law Rev 90:837

Mueller ET (2014) Commonsense reasoning: an event calculus based approach. Morgan Kaufmann, Burlington

Pearl J (2009) Causality. Cambridge University Press, Cambridge

Pennington N, Hastie R (1993) Reasoning in explanation-based decision making. Cognition 49(1):123-163

Piasecki K (2016) Kodeks postępowania cywilnego. Tom I. Komentarz do art. 1-366. C.H. Beck, Warszawa

Pinker S (2007) The stuff of thought: language as a window into human nature. Penguin, Westminster

Pollock JL (1987) Defeasible reasoning. Cogn Sci 11(4):481-518

Prakken H (1993) A logical framework for modelling legal argument. In: Proceedings of the 4th international conference on artificial intelligence and law, ACM, pp 1-9

Prakken H (2008) Formalising ordinary legal disputes: a case study. Artif Intell Law 16(4):333-359

Rawls J (1955) Two concepts of rules. Philos Rev 64(1):3-32

Reed C, Rowe G (2004) Araucaria: software for argument analysis, diagramming and representation. Int J Artif Intell Tools 13(04):961-979

Rissland EL, Skalak DB, Friedman MT (1996) Bankxx: supporting legal arguments through heuristic retrieval. Artif Intell Law 4(1):1-71

Rosa DE, Carbonera JL, Torres GM, Abel M (2012) Using events from UFO-B in an ontology collaborative construction environment. In: ONTOBRAS-MOST, pp 278-283

Rosati R (2006) Dl+log: tight integration of description logics and disjunctive datalog. In: Proceedings of the tenth international conference on principles of knowledge representation and reasoning (KR 2006), pp 68-78

Ross A (1957) Tû-tû. Harv Law Rev 70:812-825

Russell S, Norvig P (2014) Artificial intelligence: a modern approach. Prentice Hall, Upper Saddle River

Russell B (1912) The problems of philosophy. Williams and Norgate, London

Sartor G (2006) Fundamental legal concepts: a formal and teleological characterisation. Artif Intell Law 14(1):101-142

Searle JR (1995) The construction of social reality. Simon and Schuster, New York

Segerberg K, Meyer J-J, Kracht M (2016) The logic of action. In: Zalta EN (ed) The Stanford encyclopedia of philosophy, winter 2016 edn. Metaphysics Research Lab, Stanford University, Stanford

Sergot M (2013) Normative positions. In: Gabbay D, Horty J, Parent X, Van Der Meyden R, Van Der Torre L (eds) Handbook of deontic logic and normative systems. College Publications, London, pp 353-406

Sergot MJ, Sadri F, Kowalski RA, Kriwaczek F, Hammond P, Cory HT (1986) The british nationality act as a logic program. Commun ACM 29(5):370-386

Shannon C (1948) A mathematical theory of communication. Bell Syst Tech J 27(5):379-423

Sileno G, Boer A, Van Engers T (2017) A Petri net-based notation for normative modeling: evaluation on deontic paradoxes. In: Mirel workshop, co-located with ICAIL 2017

Skalak DB, Rissland EL (1992) Arguments and cases: an inevitable intertwining. Artif Intell Law 1(1):3-44

Solan LM, Darley JM (2001) Causation, contribution, and legal liability: an empirical study. Law Contemp Probl 64(4):265-298

Talmy L (1988) Force dynamics in language and cognition. Cogn Sci 12(1):49-100

Tiersma PM, Solan L (2012) The Oxford handbook of language and law. Oxford University Press, Oxford 
Timmer S, Prakken H, Meyer J-JC, Renooij S, Verheij B (2014) Extracting legal arguments from forensic Bayesian networks. In: JURIX 2014: the twenty-seventh annual conference legal knowledge and information systems. IOS Press, vol 271, pp 71-80

Toulmin S (1958) The uses of argument. Cambridge University Press, Cambridge

Valente A (1995) Legal knowledge engineering. IOS Press, Amsterdam

Van Doesburg R, Van Der Storm T, Van Engers T (2016a) Calculemus: towards a formal language for the interpretation of normative systems. AI4J Artif Intell Justice 1:73

Van Doesburg R, et al (2016b) Towards a method for a formal analysis of law, study case report. In: ICT with industry workshop 2015, NWO. https://www.nwo.nl/over-nwo/organisatie/nwo-onderdelen/ ew/bijeenkomsten/ict+with+industry+workshop/proceedings. Accessed 01 June 2017

Van Doesburg R, Van Engers T (2017) Arguments on the correct interpretation of sources of law. In: Proceedings of AICOL (In Press)

Van Eemeren FH, Garssen B, Krabbe EC, Henkemans AFS, Verheij B, Wagemans JH (2014) Handbook of argumentation theory. Springer, Berlin

Van Engers T, Boer A (2011) Public agility and change in a network environment. JeDEM-eJ eDemocr Open Gov 3(1):99-117

Van Engers T, Van Doesburg R (2016) Modeling the interpretation of sources of norms. In: Proceedings of eKNOW, pp 41-50

Van Engers TM, Kordelaar PJ, Den Hartog J, Glassée E (2000) Power: programme for an ontology based working environment for modeling and use of regulations and legislation. In: Proceedings of 11 th international workshop on database and expert systems applications, IEEE, pp 327-334

Van Kralingen RW (1995) Frame-based conceptual models of statute law. Kluwer Law International, Alphen aan den Rijn

Van Kralingen RW, Visser PR, Bench-Capon TJ, Van Den Herik HJ (1999) A principled approach to developing legal knowledge systems. Int J Hum Comput Stud 51(6):1127-1154

Verheij B (2003) Dialectical argumentation with argumentation schemes: an approach to legal logic. Artif Intell Law 11(2):167-195

Verheij B, Bex F, Timmer ST, Vlek CS, Meyer J-JC, Renooij S, Prakken H (2015) Arguments, scenarios and probabilities: connections between three normative frameworks for evidential reasoning. Law Prob Risk 15(1):35-70

Visser PR (1995) Knowledge specification for multiple legal tasks: a case study of the interaction problem in the legal domain. Kluwer Law International, Alphen aan den Rijn

Vlek CS, Prakken H, Renooij S, Verheij B (2014) Building bayesian networks for legal evidence with narratives: a case study evaluation. Artif Intell Law 22(4):375-421

Von Wright GH (1963) Norm and action: a logical enquiry. Routledge and Kegan Paul, Abingdon

Walton D (2005) Argumentation methods for artificial intelligence in law. Springer, Berlin

Walton D, Sartor G, Macagno F (2016) An argumentation framework for contested cases of statutory interpretation. Artif Intell Law 24(1):51-91

Wellman C (1990) Relative duties in the law. Philos Top 18(1):183-202

Wenar L (2005) The nature of rights. Philos Public Affairs 33(3):223-252

Wigmore JH (1937) The science of judicial proof, as given by logic, psychology, and general experience, and illustrated in judicial trials. Little Brown, and Co., Boston

Wright RW (1985) Causation in tort law. Calif Law Rev 73(6):1735-1828

Wright RW (2011) The NESS account of natural causation: a response to criticisms. http://scholarship. kentlaw.iit.edu/fac_school/716. Accessed 1 May 2017

Wyner A, Van Engers T, Hunter A (2016) Working on the argument pipeline: through flow issues between natural language argument, instantiated arguments, and argumentation frameworks. Argum Comput 7(1):69-89

Zieliński A (2017) Kodeks postępowania cywilnego. Komentarz, C.H. Beck, Warszawa

Ziembiński Z (1978) Teoria prawa, Poznań - Warszawa 